USDA

United States

Department

Forest Service

Forest Service

Rocky Mountain

Research Station

General Technical

Report RMRS-GTR-62

September 2000

[4⿻肀二4s:

\section{Assessment and Response to Bark Beetle Outbreaks in the Rocky Mountain Area}

Report to Congress from Forest Health Protection Washington Office

Forest Service

U.S. Department of Agriculture

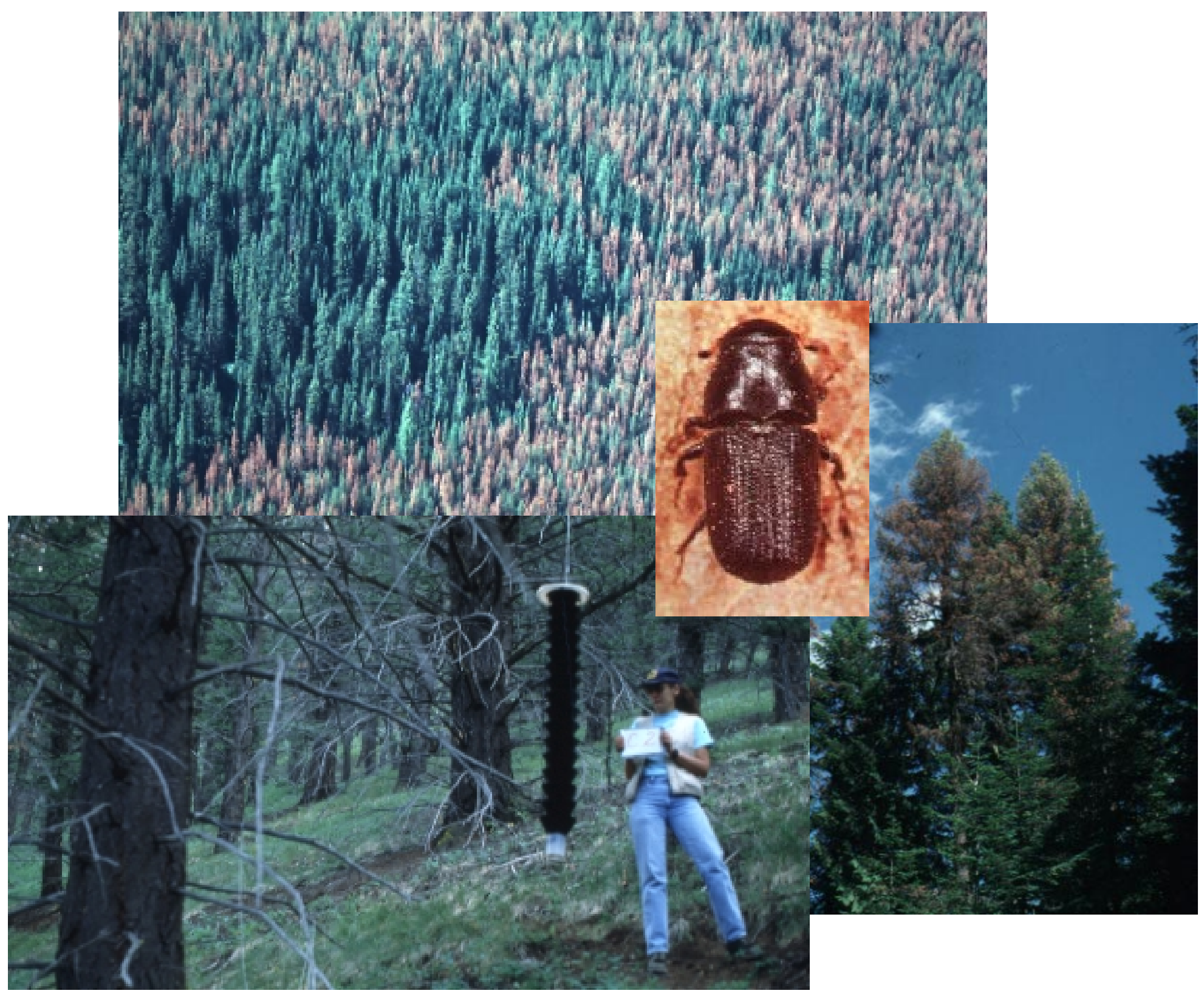




\section{Abstract}

Samman, Safiya; Logan, Jesse, tech. eds. 2000. Assessment and response to bark beetle outbreaks in the Rocky Mountain area. Report to Congress from Forest Health Protection, Washington Office, Forest Service, U.S. Department of Agriculture. Gen. Tech. Rep. RMRS-GTR-62. Ogden, UT:U.S. Department of Agriculture, Forest Service, Rocky Mountain Research Station. 46 p.

Bark beetles act as "agents of change" within the conifer forests of the Rocky Mountain area. They play a critical role in the development, senescence, and rebirth of Western forests. Bark beetle-caused tree mortality can be extensive, covering thousands of acres. This report is the Forest Service response to a Congressional direction in the FY2000 Interior and Related Agencies Appropriations Act asking for the causes, effects, and management options for native bark beetle outbreaks in the Rocky Mountain area. This report focuses on three principal species: mountain pine beetle, spruce beetle, and Douglas-fir beetle. Forest management practices subsequent to EuroAmerican colonization have significantly altered forest structure and diversity. Many forested landscapes in the Rocky Mountain area are composed of overstocked stands with decreased biodiversity. As a result, larger, more contiguous landscapes in these areas have become simultaneously susceptible to bark beetle outbreaks. A combination of biotic and abiotic factors often must occur before an outbreak develops. In some ecosystems (such as lodgepole pine), beetle outbreaks and subsequent fires are often stand-replacing events critical to maintaining the species over much of its distribution. Bark beetle-caused tree mortality also provides important habitat for some species of wildlife, provides coarse woody debris to streams, and contributes to nutrient recycling. Negative effects on wild life include loss of hiding cover and older tree habitat crucial for some species of threatened and endangered wildlife. Outbreaks can severely affect resource objectives, particularly in high-value recreation areas, watersheds, and wildland/urban interface landscapes, and impact timber production sites.

Effective management strategies for direct and indirect control of bark beetle populations include prevention, suppression, and restoration. Prevention strategies are designed to change forest conditions that render them susceptible to bark beetle. Suppression strategies are designed to suppress or control existing populations of the insect. Restoration strategies reestablish ecosystem's ecological integrity to a degree to which the ecosystem's components and their relationships are present, functioning, and capable of self-renewal. All three strategies are needed to formulate an effective bark beetle management policy.

Formulation of an effective management strategy faces significant challenges resulting from conflicting objectives when combining ecological principles and social constraints. The Rocky Mountain area requires a comprehensive strategy that addresses multiple land-use objectives, specific bark beetle species, and site conditions. To develop this strategy and implement these activities, we must address a myriad of needs, including public education, research, technology transfer, early detection, and monitoring.

Key words: biodiversity, ecosystem management, landscape assessments, Dentroctonus, mountain pine beetle, Douglas-fir beetle, spruce beetle

\section{Pesticide Precautionary Statement}

This publication reports research involving pesticides. It does not contain recommendations for their use, nor does it imply that the uses discussed here have been registered. All uses of pesticides must be registered by appropriate State and/or Federal agencies before they can be recommended.

CAUTION: Pesticides can be injurious to humans, domestic animals, desirable plants, and fish or other wildlife-if they are not handled or applied properly. Use all pesticides selectively and carefully. Follow recommended practices for the disposal of surplus pesticides and pesticide containers.

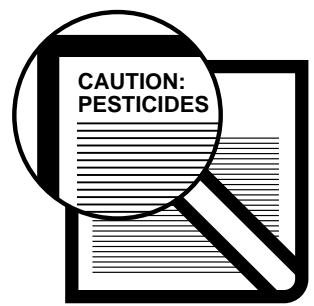




\section{Assessment and Response to Bark Beetle Outbreaks in the Rocky Mountain Area}

Report to Congress from

Forest Health Protection

Washington Office

Forest Service

U.S. Department of Agriculture

\section{Team Leaders and Technical Editors}

Safiya Samman, USDA Forest Service, Washington Office, Forest Health Protection Jesse Logan, Research Entomologist, USDA Forest Service, Rocky Mountain Research Station

\section{Team Members}

Barbara Bentz, Research Entomologist, USDA Forest Service, Rocky Mountain Research Station Jimmie Chew, Ecologist, USDA Forest Service, Rocky Mountain Research Station Marla Downing, Program Manager, USDA Forest Service, Forest Health Technology Enterprise Team Tom Eager, Entomologist, USDA Forest Service, Rocky Mountain Region Ken Gibson, Entomologist, USDA Forest Service, Northern Region Dave Leatherman, Entomologist, Colorado State Forest Service Ladd Livingston, Entomologist, Idaho Department of Lands Steven Munson, Entomologist, USDA Forest Service, Intermountain Region Bruce Short, Regional Silviculturist, USDA Forest Service, Rocky Mountain Region Wini Sorensen, Fire Ecologist, USDA Forest Service, Intermountain Region 


\section{TABLE OF CONTENTS}

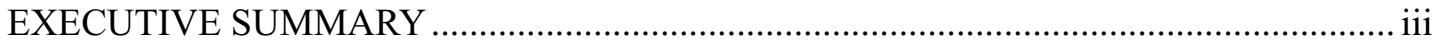

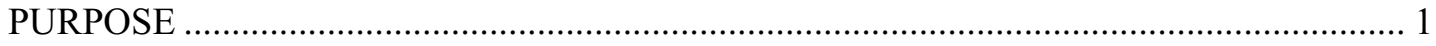

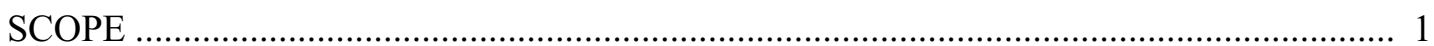

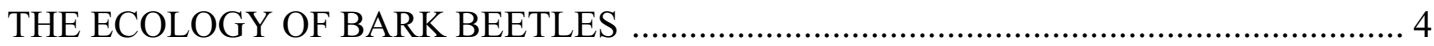

FACTORS AFFECTING BARK BEETLE POPULATIONS ................................................. 8

Biotic Factors Affecting Bark Beetle Populations ......................................................... 8

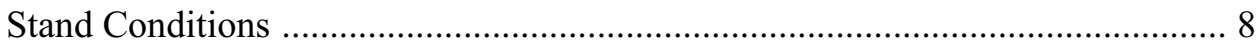

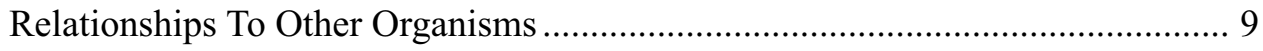

Abiotic Factors Influencing Bark Beetle Populations ................................................. 10

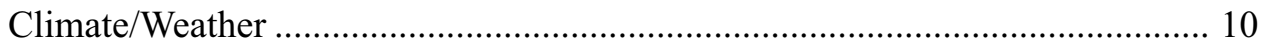

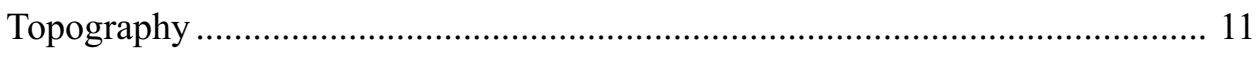

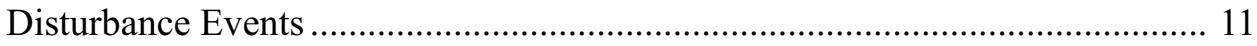

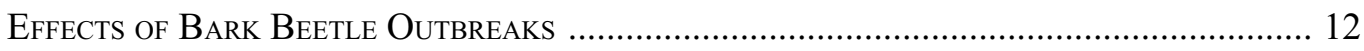

Biological Effects ................................................................................ 12

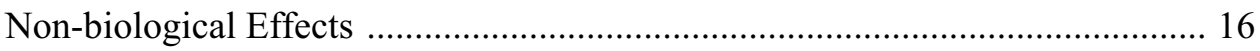

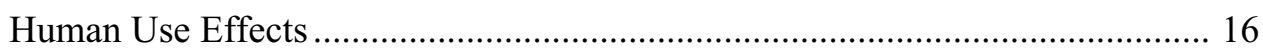

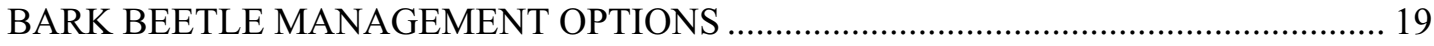

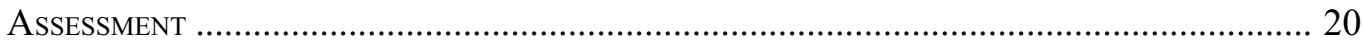

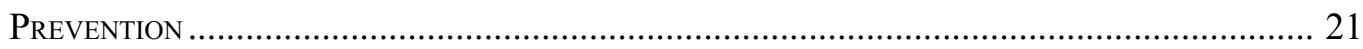

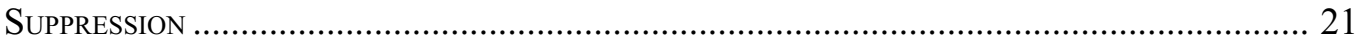

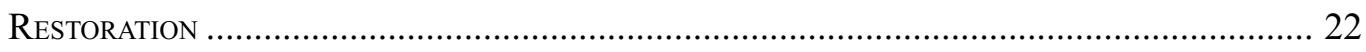

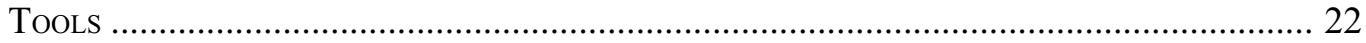

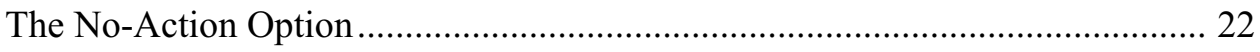

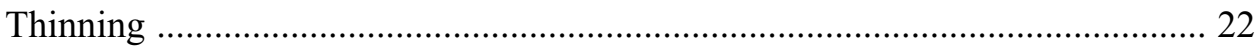

Fire

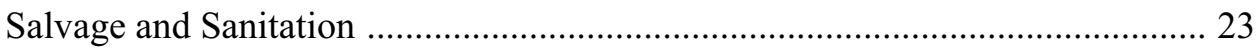

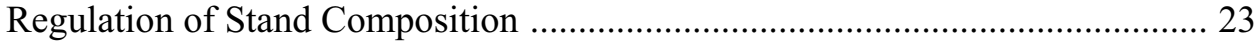

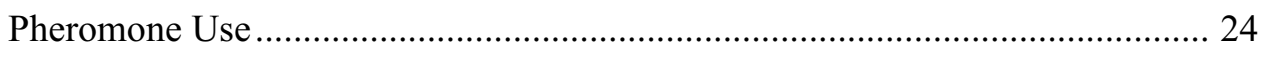

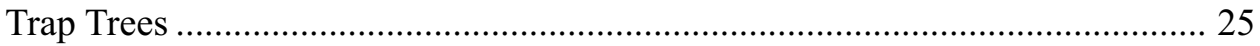




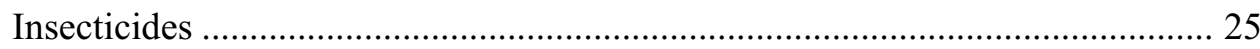

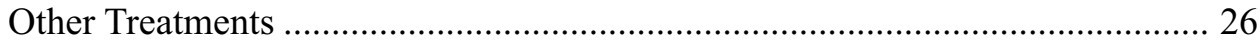

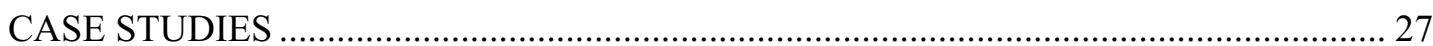

Spruce Beetle on Federal and State Lands in the Payette Lake Area of

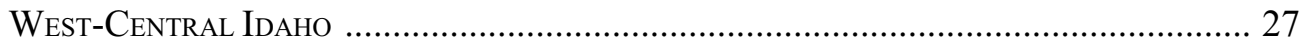

Bark Beetle Recovery Project on the Dixie National Forest in Southern Utah ...... 28

The Upper South Platte Watershed Protection and Restoration Project,

Pike-San Isabel National Forest and Mixed-Ownership Lands in Colorado ....... 29

Restoration of Lodgepole Pine Stands on the Sawtooth National

Recreation Area In Central Idaho ................................................................... 30

A No-Action Strategy in Pinyon Pine on the Coconino National Forest

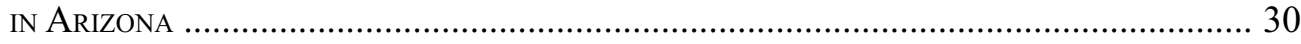

Mountain Pine Beetle Outbreak in the Vail Valley, Colorado ................................... 31

BARK BEETLE MANAGEMENT AND LAND-USE OPTIONS ................................. 33

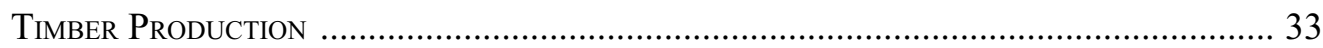

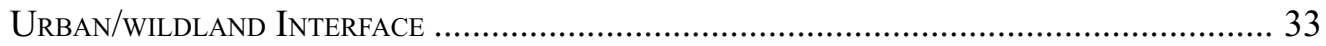

WiLDERNESS AND RoAdLESS AREAS _.......................................................................... 33

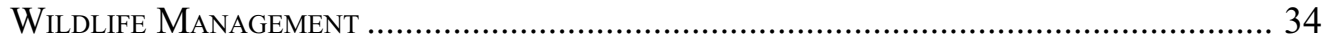

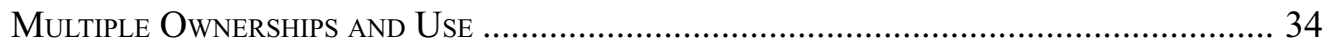

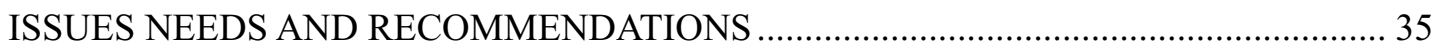

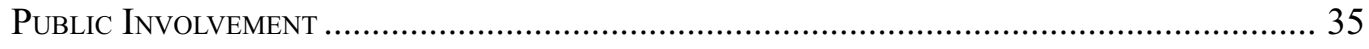

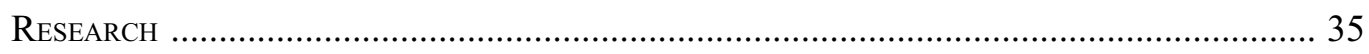

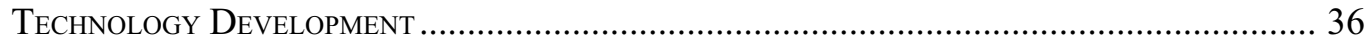

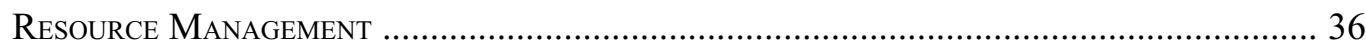

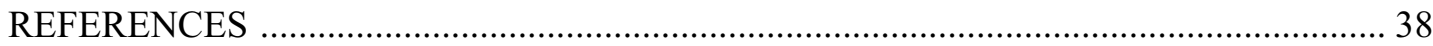

Social and Ecological Influences on Forest Ecology ……....................................... 38

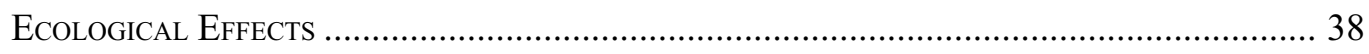

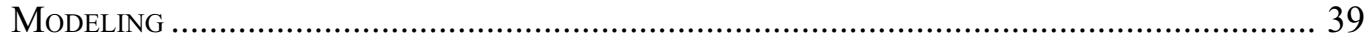

Vegetation Management/Suppression/PreVention ..................................................... 40

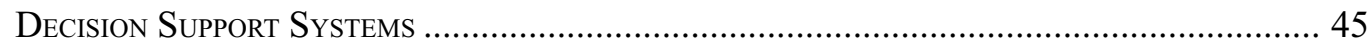

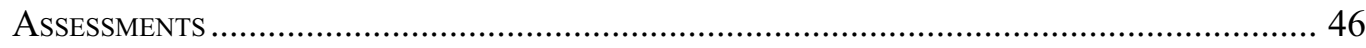




\section{EXECUTIVE SUMMARY}

This report is the Forest Service response to a Congressional direction in the FY2000 Interior and Related Agencies Appropriations Act. It addresses the causes, effects and management options for native bark beetle outbreaks in the Rocky Mountain area. Managing bark beetle populations to meet a variety of resource objectives is a complex issue. Although there are many native species of bark beetles responsible for tree mortality in the Rocky Mountain area, this report focuses on three principal species: mountain pine beetle, spruce beetle, and Douglas-fir beetle.

Periodic outbreaks of native bark beetle species have occurred for thousands of years. These natural disturbance agents and their relationship within a healthy, functioning ecosystem are still not well-understood: further research is required to answer questions related to the bark beetles role within a functioning ecosystem and to address changing resource values in this region. However, entomologists do possess important knowledge regarding causes and effects of bark beetle outbreaks. They can and do provide management options for bark beetles that address a variety of resource issues such as: urban/wildland interface development, recreation, wildlife, wood fiber, scenic beauty, and water quality.

\section{Causes of Bark Beetle Outbreaks}

Forest management practices subsequent to Euro-American colonization have significantly altered forest structure and diversity. Many forested landscapes in the Rocky Mountain area are composed of overstocked stands with decreased biodiversity. As a result, larger, more contiguous landscapes in these areas have become simultaneously susceptible to bark beetle outbreaks.

Both biotic and abiotic factors affect bark beetle population development and spread. Biotic factors include bark beetle population biology, and the type, age, and distribution of tree species. Abiotic factors such as climate, geographic location, avalanches, landslides, human-caused disturbance (logging, road building, etc.), and weather related phenomena such as extended periods of drought and high winds can act as a trigger for outbreaks. A combination of the above factors often must occur before an outbreak develops.

\section{Effects of Bark Beetle Outbreaks}

Bark beetles act as "agents of change" within the conifer forests of the Rocky Mountain area. They play a critical role in the development, senescence, and rebirth of Western forests. Bark beetle-caused tree mortality can be extensive, covering thousands of acres.

In some ecosystems (such as lodgepole pine), beetle outbreaks and subsequent fires are often stand-replacing events critical to maintaining the species over much of its distribution. Bark beetle-caused tree mortality also provides important habitat for some species of wildlife, provides coarse woody debris to streams, and contributes to nutrient recycling. However, bark beetle outbreaks may also have negative effects on wildlife, including loss of hiding cover and older tree habitat crucial for some species of threatened and endangered wildlife. Outbreaks can severely affect resource objectives, particularly in high-value recreation areas, watersheds, and wildland/urban interface landscapes, and impact timber production sites. 


\section{Management Options for Bark Beetle Outbreaks}

Bark beetles are native species, and they play an ecologically important role in the ecosystem. Management strategies should not be developed to eradicate populations of bark beetles. Not only is eradication infeasible, the loss of bark beetles from an ecosystem could adversely alter ecosystem processes and functions.

Resource managers are faced with a variety of conflicting objectives related to bark beetle outbreaks: for instance, forest habitat that is preferred by certain species of wildlife may be susceptible to bark beetle outbreaks. The land use objectives and the scale at which tree mortality could or does occur are the most important factors that should be weighed when evaluating beneficial and negative effects of bark beetle tree mortality. Designing an effective bark beetle management strategy thus depends on the particular bark beetle species in question, site and tree conditions, and determining which resource objectives to address.

There is an assortment of effective management strategies available to resource managers for direct and indirect control of bark beetle populations. Treatment strategies for bark beetle management include the following three categories: prevention, suppression, and restoration.

Prevention includes treatment strategies designed to change forest conditions that render them susceptible to bark beetle. Prevention tactics implemented before an outbreak occurs are designed to address stand susceptibility across forested landscapes. Prevention strategies encompass long-term treatments that require multiple stand entries. This series of treatments will result in reduced stand susceptibility for many years. For some bark beetle species and their hosts, there are effective prevention strategies available. For others, further research is required to improve or develop long-term preventive treatments designed to meet ecological needs and resource objectives.

Suppression strategies are designed to suppress or control existing populations of the insect. These tactics are often short-term and are not initiated to modify existing susceptible stand characteristics. Suppression may not be an effective alternative if the population is too large and widespread. This tactic may also be ineffective if adjacent ownerships do not apply treatments, or populations occur within landscapes where resource objectives do not permit suppressive treatments to address expanding bark beetle populations.

Restoration is a management strategy to reestablish ecosystem's ecological integrity to a degree to which the ecosystem's components and their relationships are present, functioning, and capable of self-renewal. This strategy includes restoring landscape diversity in species, age, and structure, permitting bark beetle populations to resume their historic beneficial role. It attempts to maintain the ecological benefits of active bark beetle populations and at the same time maintain populations within acceptable limits. Done correctly, this approach will create a landscape mosaic of forest types that contain all critical components of an ecosystem required to meet specified landuse objectives.

All three strategies are needed in order to formulate an effective bark beetle management policy. 
Formulation of an effective management strategy for bark beetles in the Rocky Mountain area faces significant challenges. These challenges result from conflicting objectives when combining ecological principles and social constraints. For these reasons, we must be flexible in adapting existing management tactics to meet the complex natural resource issues and objectives of the area.

Economically efficient and ecologically sound management activities require landscapelevel assessments. Often these large-scale assessments call for a coordinated approach between all forest ownerships. In the Rocky Mountain area, this is a complex task requiring a comprehensive strategy that addresses multiple land-use objectives, specific bark beetle species, and site conditions. To develop this strategy and implement these activities, we must address a myriad of needs, including public education, research, technology transfer, early detection, and monitoring. 


\title{
Assessment and Response to Bark Beetle Outbreaks in the Rocky Mountain Area
}

\author{
Report to Congress from \\ Forest Health Protection \\ Washington Office \\ Forest Service \\ U.S. Department of Agriculture
}

\section{PURPOSE}

This report represents Forest Service response to a Congressional direction in the FY2000 Interior and Related Agencies Appropriations Act. The language of the Act states:

The committees direct the Forest Service to improve the control or eradication of the pine beetles in the Rocky Mountain region of the United States; to conduct a study of the causes and effects of, and solutions for, the infestation of pine beetles in the Rocky Mountain region of the United States; and to submit to the House and Senate Committees on Appropriations a report on the results of the study within six months of enactment of this bill.

The report addresses causes and effects of bark beetle outbreaks in the Rocky Mountains. It also provides options and future directions that discuss prevention and suppression strategies to mitigate bark beetle effects.

\section{SCOPE}

The scope of this report is to address the following areas:

- To describe the role of bark beetles in the coniferous forests of the Rocky Mountain area of the United States and factors affecting beetle population outbreaks.

- To describe potential management strategies for control of bark beetle outbreaks.

- To describe the history and response to previous bark beetle outbreaks and their outcomes.

- To describe issues, needs, and recommendations for future response to bark beetle outbreaks.

While there are many bark beetles affecting the forests of the Rocky Mountain area, this report concentrates on the three (i.e., mountain pine beetle, Douglas-fir beetle, and spruce beetle) that are responsible for the majority of the beetle-caused mortality. The area of consideration includes all forestlands in the Rocky Mountain area (Figure 1); approximately 90 percent of these forestlands are Federally owned. 

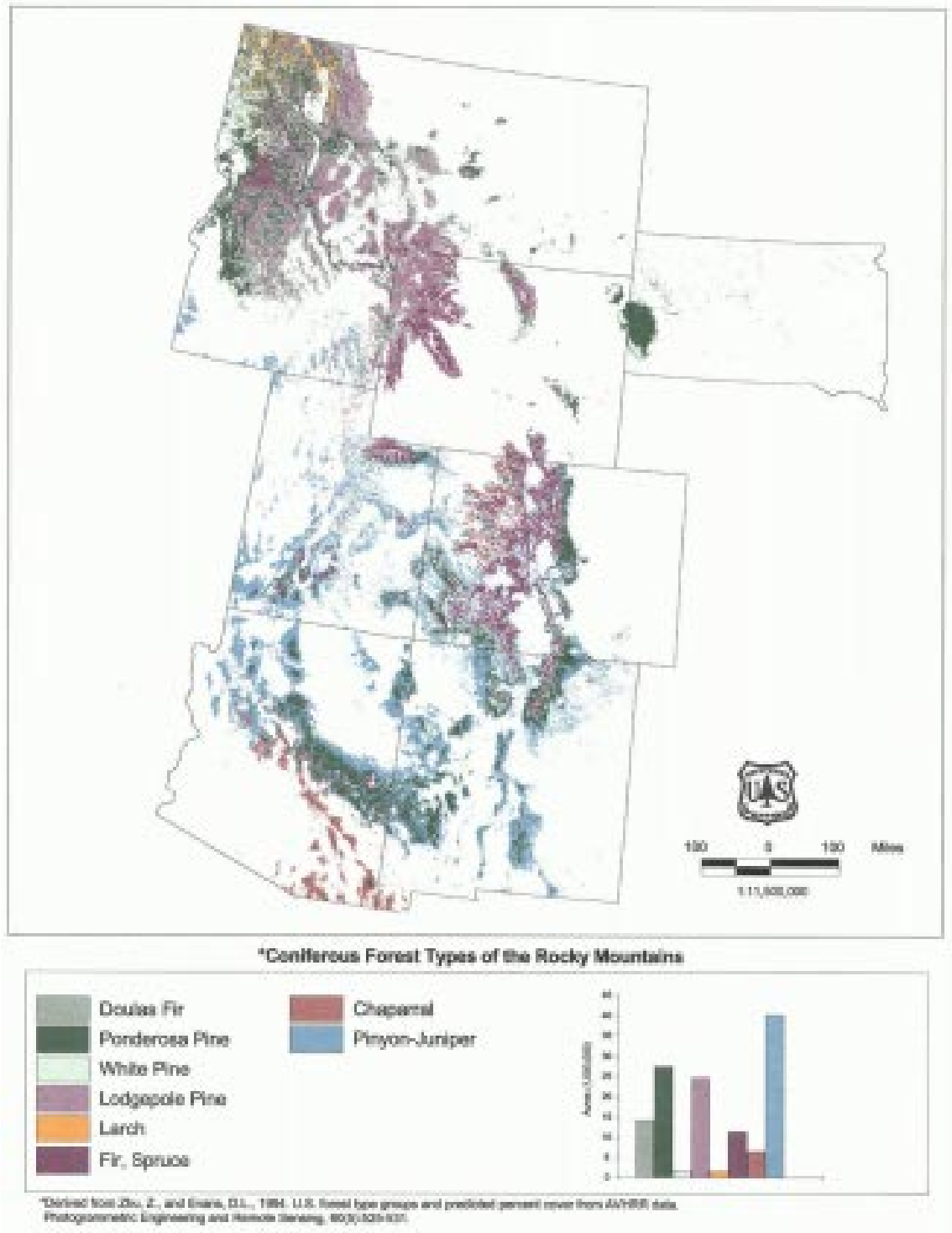

Figure 1. The Rocky Mountain area studied in this report.

The primary sources of information for this report came from specialists in the Forest Service and State agencies who have extensive experience in the Rocky Mountain area. To enhance readability, we have not cited references or included scientific names of trees, insects, and fungi in the text. Selected references are listed at the end of the report.

The following are members of the team contributing to this paper:

Team Leaders:

- Safiya Samman, USDA Forest Service, Washington Office, Forest Health Protection

- Jesse Logan, Research Entomologist, USDA Forest Service, Rocky Mountain Research Station 
Team Members:

- Barbara Bentz, Research Entomologist, USDA Forest Service, Rocky Mountain Research Station

- Jimmie Chew, Ecologist, USDA Forest Service, Rocky Mountain Research Station

- Marla Downing, Program Manager, USDA Forest Service, Forest Health Technology Enterprise Team

- Tom Eager, Entomologist, USDA Forest Service, Rocky Mountain Region

- Ken Gibson, Entomologist, USDA Forest Service, Northern Region

- Dave Leatherman, Entomologist, Colorado State Forest Service

- Ladd Livingston, Entomologist, Idaho Department of Lands

- Steven Munson, Entomologist USDA Forest Service, Intermountain Region

- Bruce Short, Regional Silviculturist, USDA Forest Service, Rocky Mountain Region

- Wini Sorensen, Fire Ecologist, USDA Forest Service, Intermountain Region 


\section{THE ECOLOGY OF BARK BEETLES}

Throughout recorded history, bark beetles have performed a major function in the development and maintenance of coniferous stands in the Rocky Mountain West. Having evolved with their respective hosts, bark beetles - often in association with fire-have been instrumental in maintaining host stands in a younger, more vigorous and often seral or early successional state. That is unquestionably the case with mountain pine beetle in its relationship with lodgepole pine, although it is less obvious with other bark beetles and the several coniferous species they attack.

At endemic levels, bark beetles beneficially remove older, weaker individuals from stands of trees, causing less than 2 percent mortality per year. Outbreaks occur when there are locally high populations of beetles, a sufficient number of susceptible host trees, and favorable environmental conditions for bark beetle survival. Stand conditions and site factors contributing to outbreaks vary somewhat with beetle species and their interactions with their hosts; but almost always require stands of older, larger diameter, less vigorous, trees. In addition, some type of disturbance can act as an outbreak "trigger." That "disturbance" may be as obvious as a wind-thrown stand, or as subtle as unusually dry conditions over several years. Bark beetles are adept at taking advantage of either, and populations will increase as conditions allow.

As individual trees become weakened and senescent, bark beetles are attracted to them as favorable sites in which to reproduce. Females initiate attacks on a host, and by means of a pheromone (a message-bearing chemical), attract mates. Male beetles produce additional pheromones, and within hours a successfully attacked tree becomes the site of a "mass attack" and the focal point of what may become a group of beetle-killed trees. How big that "group" becomes depends upon stand and environmental conditions, and on nearby populations of beetles (Figure 2).

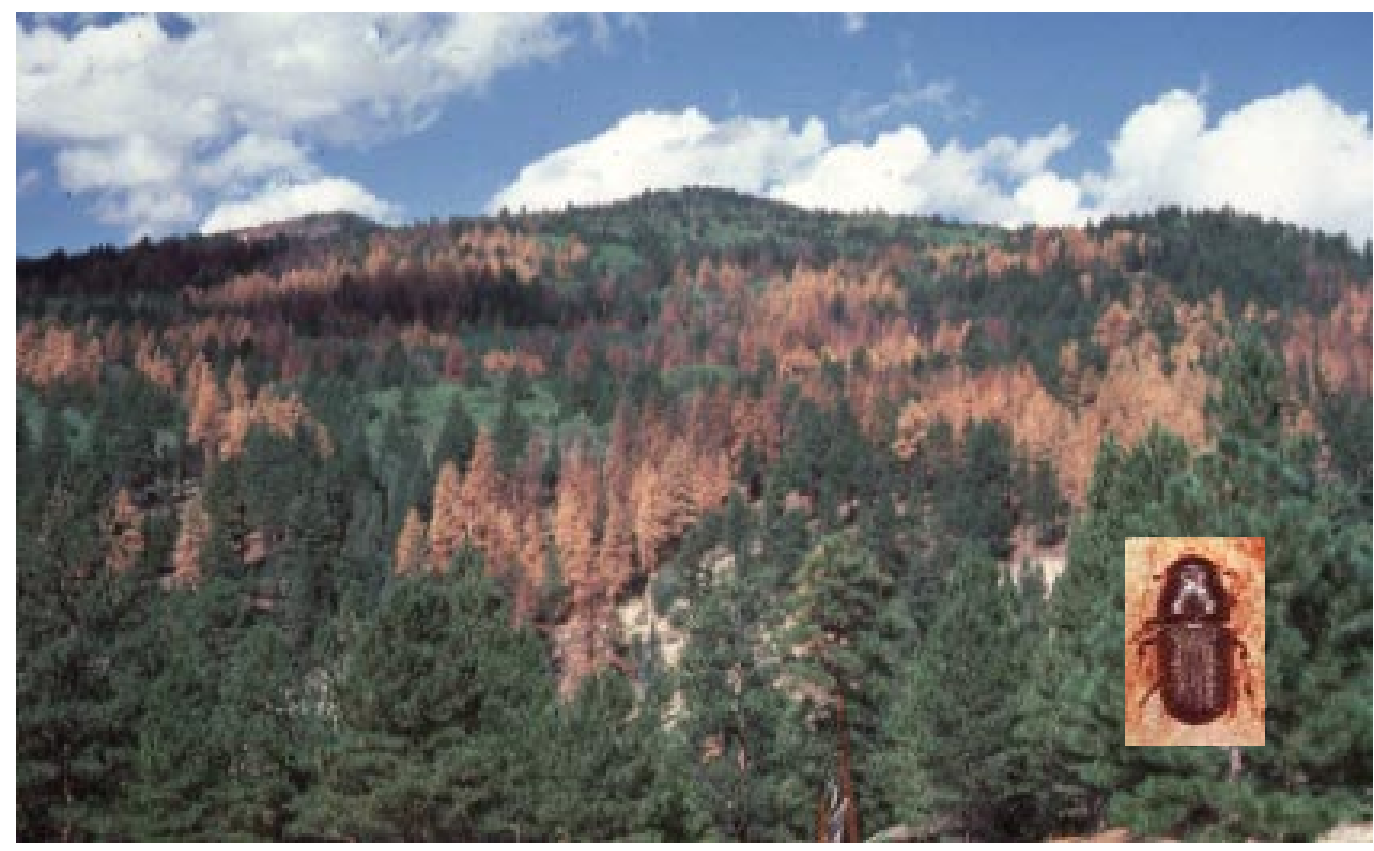

Figure 2. A group mountain pine bark beetle kill in ponderosa pine, Dixie National Forest, Utah. 
An individual female may lay in excess of 100 eggs. As eggs hatch, larvae construct feeding galleries in the phloem (the inner bark of the tree). These galleries eventually girdle and kill the tree by cutting off the exchange of nutrients between the roots and the crown of the tree (Figure 3 ).

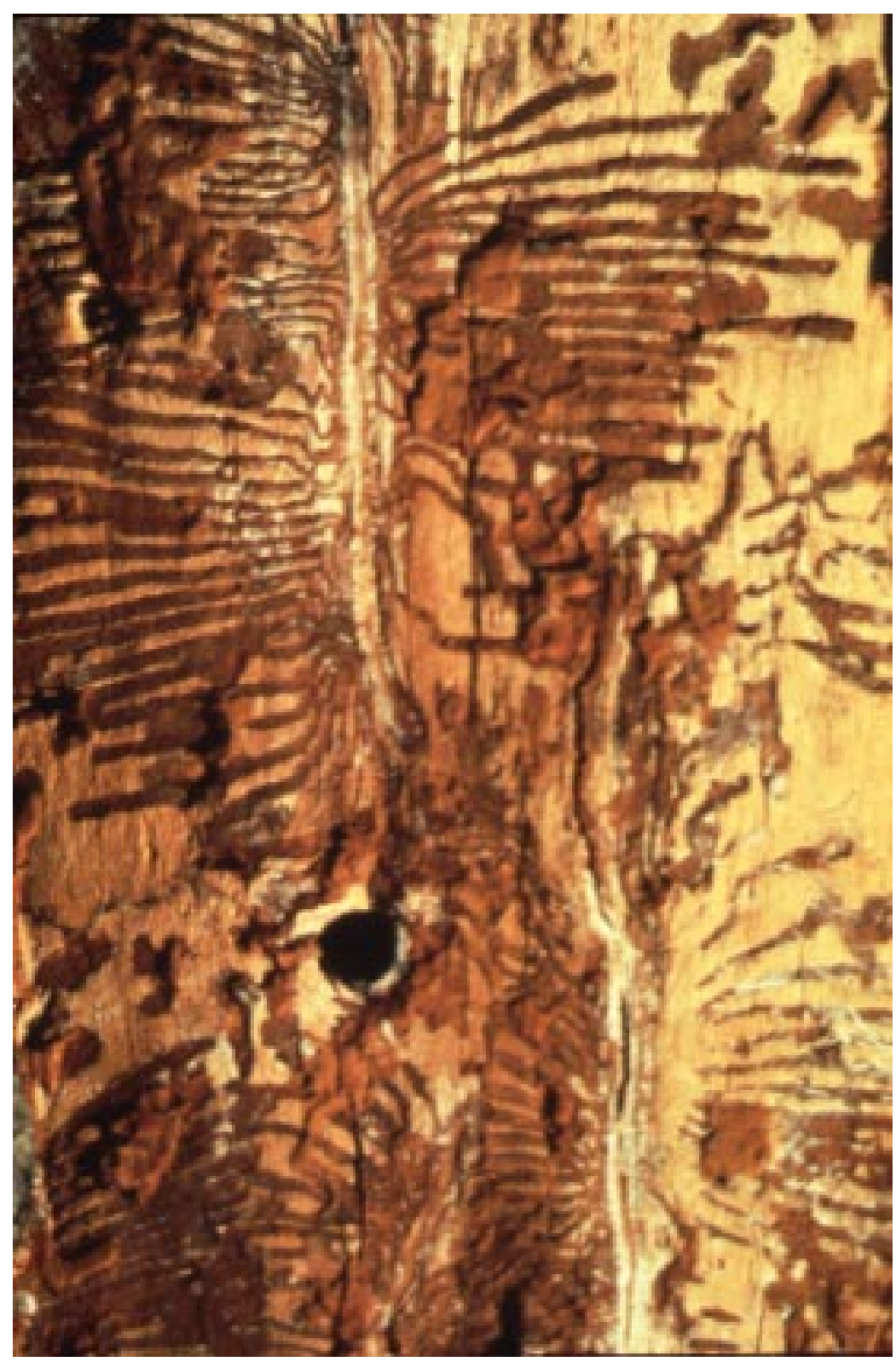

Figure 3. Douglas-fir beetle galleries beneath the outer bark.

Most bark beetle species produce one generation each year (Figure 4). A few, such as spruce beetle, typically require 2 years for each generation. Other beetles produce multiple generations per year. 

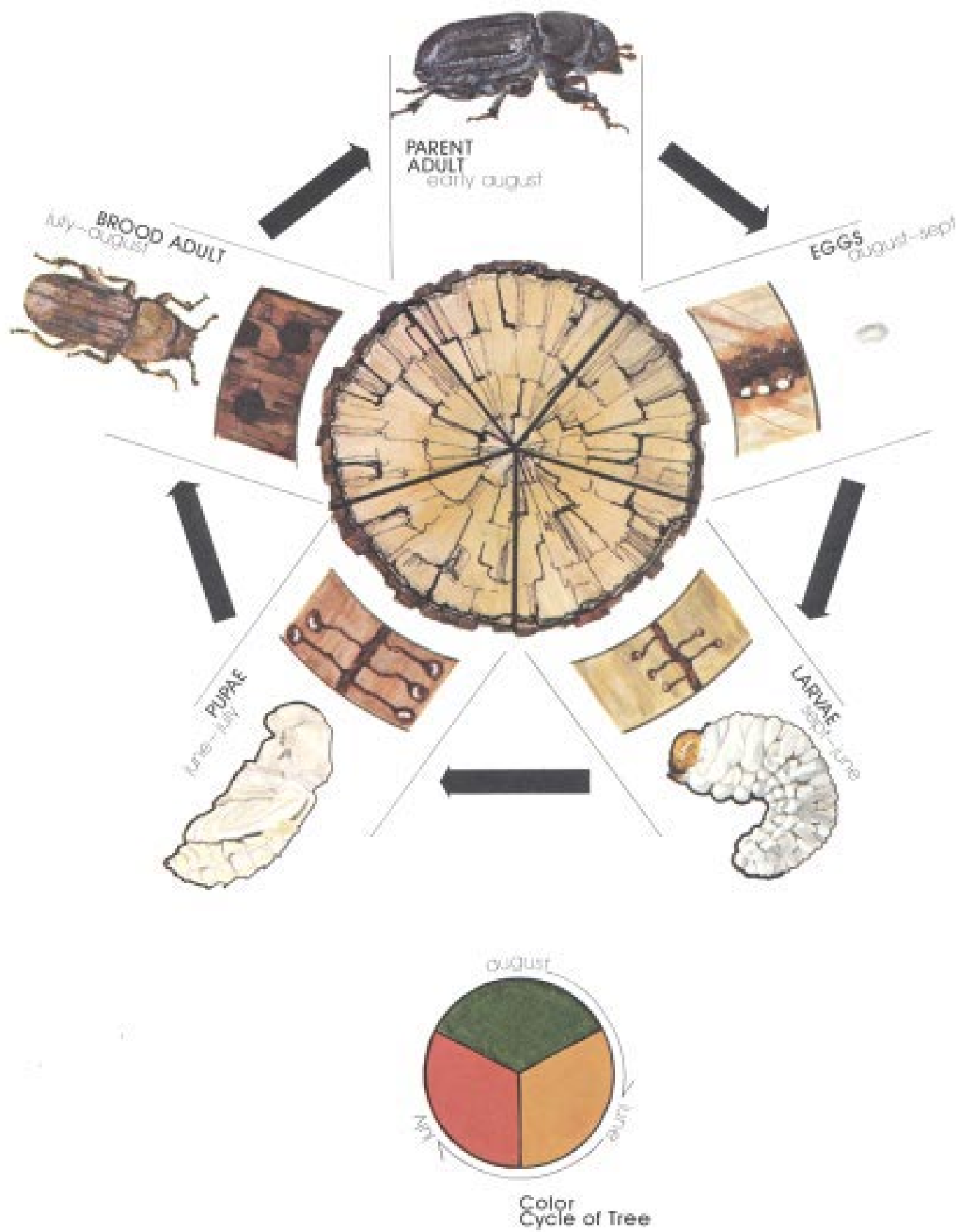

Figure 4. Mountain pine beetle life cycle.

The most damaging bark beetles belong to the genus Dendroctonus. The most widespread and serious of those are mountain pine beetle, Douglas-fir beetle, and spruce beetle. Of lesser importance, but occasionally causing significant mortality in various locations of the Rocky Mountains, are western pine beetle, fir engraver, roundheaded pine beetle, and western balsam bark beetle complex (western balsam bark beetle, other bark beetles, and in some areas, root disease) in subalpine fir. 
Although bark beetle outbreaks are important in the ecological development of a forest landscape, resulting levels of tree mortality may exceed desirable levels, affecting multiple resource objectives including timber, wildlife, and recreation. Beetle populations throughout the Rocky Mountains have resulted in the death of over 7 million trees from 1995 to 1999 (Figure 5). Locally intense outbreaks can affect management decisions and detract from the many resource and social amenities realized from forested ecosystems.

\section{TREES KILLED BY MAJOR BARK BEETLES \\ IN THE ROCKY MOUNTAIN AREA 1995 -1999}

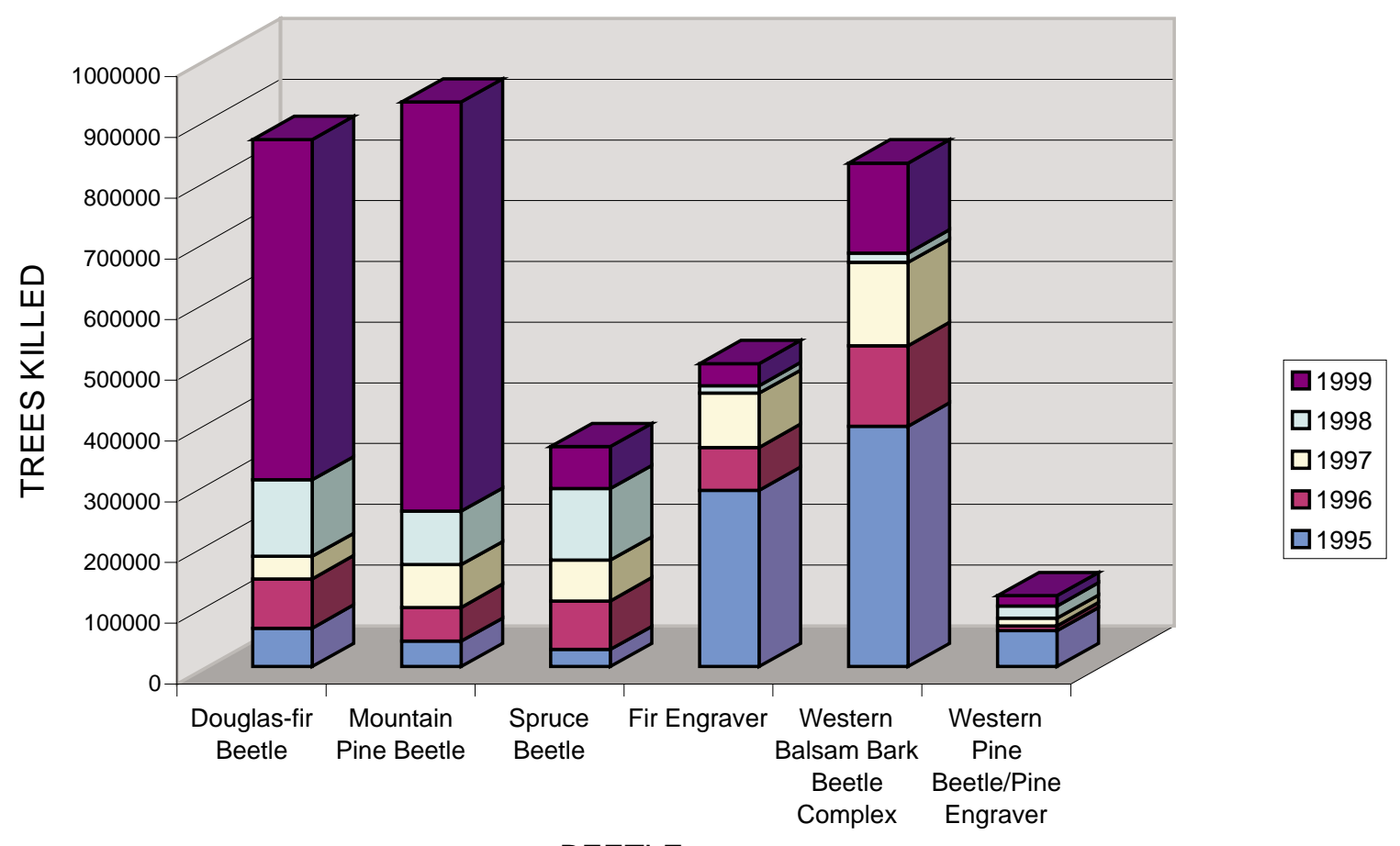

BEETLE

Figure 5. Bark beetle mortality by species. 


\section{FACTORS AFFECTING BARK BEETLE POPULATIONS}

There is no single predictor of bark beetle population increases. Rather, outbreaks are the result of one or more interactive factors that determine the rate of increase and the number of bark beetles that emerge at a specific time. These factors are biotic (biological: i.e., having to do with the beetles, their hosts, and their predators) and abiotic (nonbiological: i.e., geographic location and topographic features, weather conditions, and the recent history of the forest, or whether large-scale disturbances have made the landscape more or less susceptible to population increases). Included in these factors are the effects of human intervention: logging and restocking history, and fire-use or fire-suppression history.

Simply put, for an outbreak of beetles to occur, the following must come together in the same location at the same time: a large number of susceptible trees, some type of triggering mechanism, and beetles.

\section{Biotic Factors Affecting Bark Beetle Populations}

The greatest biotic factor affecting bark beetle populations is the availability of food, which is determined by conditions in their host species within the forest. Given the availability of food to support a population increase, other factors contribute to or check the growth of these populations. This section concentrates on how the trees, and other key nonhost organisms, influence bark beetle population dynamics.

\section{Stand Conditions}

A group of trees that are fairly uniform in makeup and differ qualitatively and quantitatively from nearby trees is often referred to as a "stand." Attributes of a given stand that generally influence bark beetle activity are:

- Species composition of the stand.

- The age/size of the trees in the stand.

- The density at which the trees are growing.

The following paragraphs describe each of these factors.

Tree Species. Bark beetles tend to be fairly host-specific: that is, a bark beetle species that attacks one tree species usually does not attack other species of conifers. Examples of bark beetles that are quite host-specific include spruce beetle and Douglas-fir beetle. However, mountain pine beetle attacks lodgepole pine, ponderosa pine, and many other species of pine, including the fiveneedle pine species growing at high elevation. Extensive stands of susceptible hosts invite bark beetle activity. Conversely, stands that contain a mixture of species are not prone to extensive tree mortality caused by one species of bark beetle.

Where stands have been logged and restocked (replanted), species composition is determined by the projected use of the forest. Where single-species restocking has been exercised, the resulting stands may provide a homogenous food source for a species of bark 
beetle. Where regeneration (renewing tree cover by establishing young trees naturally or artificially) has included multiple species, this diversity does not favor a single beetle species.

Tree Age/Size. The three bark beetle species considered here prefer mature trees. These tend to be the biggest, oldest, and slowest-growing trees in the forest (Figure 6). However, during epidemics, prolific numbers of beetles are produced, overpowering the defensive capabilities of any acceptable tree.

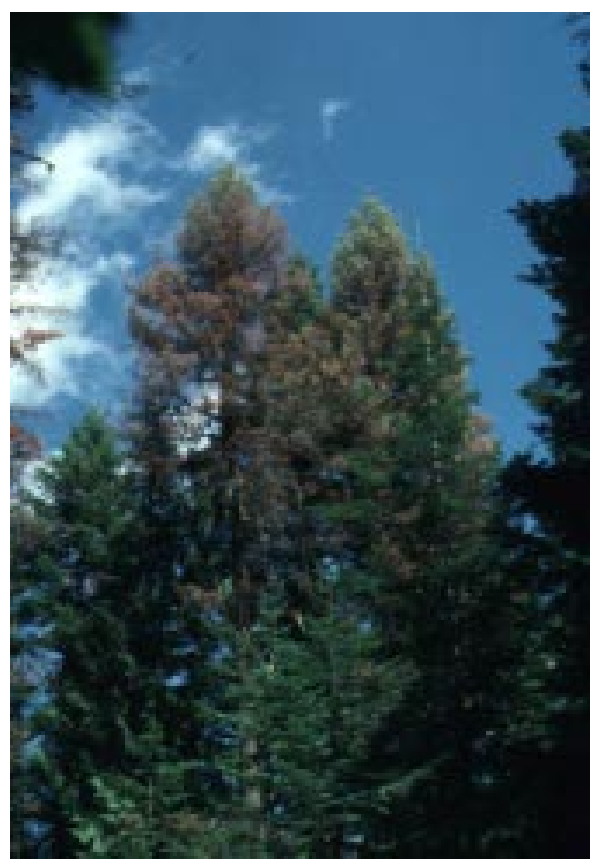

Figure 6. Attacked mature Douglas-fir showing crown discoloration, Idaho Panhandle National Forests.

Stand Density. The density of trees per unit area influences beetle behavior. Bark beetle outbreaks generally occur in dense stands. Research and experience indicate that, in stands of lodgepole and ponderosa pine, increased spacing between trees decreases susceptibility. Many forest stands in the Rocky Mountain area are composed of tree densities susceptible to attack by bark beetles.

\section{Relationships To Other Organisms}

Bark beetles interact, not only with their host trees, but with other organisms in the forest as well. Other organisms that influence bark beetle populations are divided into two categories: those that "predispose" trees to attack, and those that regulate bark beetle populations, such as parasites and predators.

Organisms that predispose trees to attack include fungal-caused tree diseases, insect defoliators, and other bark beetles. Control of these organisms in our land management practices indirectly affects bark beetle behavior and spread.

Organisms that regulate bark beetle populations do so by feeding on bark beetles. Among birds, woodpeckers are particularly dependent on bark beetles for food and creating dead trees for nests. Although an important predator of bark beetles, woodpecker populations rarely "prevent" 
bark beetle populations from expanding when other conditions for expansion are favorable. But they can exert some population control affecting localized or concentrated populations of bark beetles at low population levels.

There are a number of invertebrate groups known to parasitize or prey on bark beetles. Some, such as clerid beetles (Figure 7), may regulate bark beetle populations.

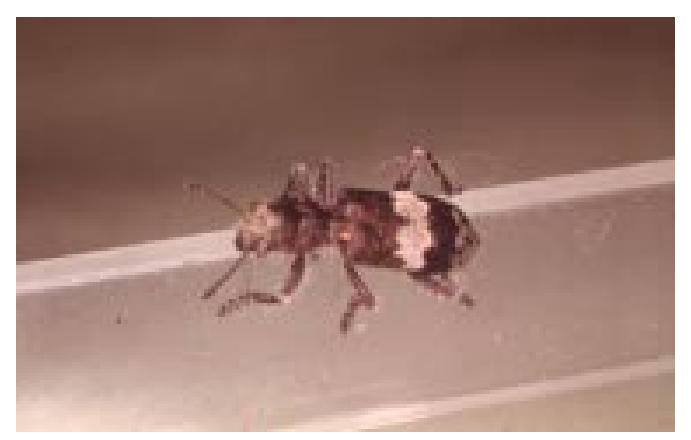

Figure 7. A clerid predator of bark beetles.

Natural enemies of pests are essential components of the food web and forest biodiversity. However, they are rarely capable of preventing a bark beetle population increase across a susceptible landscape.

\section{Abiotic Factors Influencing Bark Beetle Populations}

Abiotic factors impact bark beetle population dynamics both directly and indirectly. These factors - climate/weather, topography, and disturbance events - may act directly to slow or accelerate population growth or may act indirectly by affecting the availability of the food supply.

\section{Climate/Weather}

"Climate" is the average condition of weather in a given place over a number of years, while "weather" is the actual state of air or atmosphere with respect to moisture, wind, clouds, and other atmospheric conditions. The climate associated with a particular geographic location may not support bark beetles in that it is simply too cold to allow populations to become established. The weather within an acceptable climate, on the other hand, may provide a range of conditions that allow bark beetle populations to fluctuate.

Seasonal weather patterns can affect bark beetle populations in several ways, some that favor population expansion and some that inhibit it. Several years of unusually warm weather and long-term droughts tend to favor population expansion. Conversely, populations are retarded by early-fall or late-spring freezes, extreme cold for extended periods in mid-winter, and cold, wet weather during adult flight. 


\section{Topography} bark beetles.

All aspects that affect local growing conditions affect the presence of suitable hosts for

Elevation/Latitude. Elements that determine the seasonal temperature and moisture norms directly affect the beetles and their microhabitat, and limit the presence of host trees. In some cases host trees exist beyond the survival limits of bark beetles. Knowledge of bark beetle ranges, as defined by elevation and latitude, can be useful in understanding historical bark beetle patterns. This information can also be used in formulating various risk-rating schemes.

Aspect. Aspect (the direction that a slope faces) of mountainous terrain determines available moisture and thus, tree species and associated bark beetles.

Slope. Slope can be a factor in bark beetle populations as it influences soil depth, soil slippage, direct disturbance from avalanches, microclimate, and root health. All of these factors can predispose trees to bark beetle attack.

\section{Disturbance Events}

Abiotic disturbance events are any nonbiological large-scale (involving one or more stands) events that affect the landscape where bark beetles are present. Examples of disturbance events are unusually high winds, destructive storms, avalanches and landslides, and fire.

Wind. Extreme winds that blow down trees can be a factor triggering massive bark beetle outbreaks as large areas of blowdown provide a ready supply of stressed and dying trees as a food supply.

Snow and Ice. Snow and ice loads can also cause large-scale disturbance. In northern Idaho, an ice storm and heavy snows in the winter of 1996/1997 felled numerous trees. This caused an increase in susceptible sites for bark beetle attacks, resulting in a large increase in bark beetle populations. The 1999 aerial detection survey documented an average of three to five dead Douglasfir trees per acre on 108,529 acres in the Idaho Panhandle National Forests. In endemic conditions, mortality is generally one tree per acre.

Landslides and Avalanches. Landslides and avalanches can create large numbers of downed trees that are then highly susceptible to spruce beetle and Douglas-fir beetle. Populations that build up in this downed material can then spread to standing trees nearby.

Fire. The effects of fire on bark beetle populations depend on fire frequency. Historically, lower elevation, drier stands tended to burn far more frequently than higher, wetter sites (fire return intervals in some forest types in the Rocky Mountains range from 10 years to every 300 to 500 years). This disturbance has resulted in a mosaic of stands of different ages and, hence, mixed susceptibility to bark beetle infestation.

Human Disturbance. Other disturbance events are human-made. Native American people manipulated forested landscapes for centuries, primarily by starting fires, mimicking (albeit accelerating) naturally occurring processes. Over the past 150 years, effective fire suppression, mining, grazing, timber extraction and restocking, and other activities have substantially altered the landscape from presettlement conditions. In general terms, these changes have resulted in 
forest landscapes with (1) increased homogeneity with respect to age and species composition, and (2) increased density of vegetative cover. Such forests are at greater risk of bark beetle attack.

\section{Effects of Bark Beetle Outbreaks}

Bark beetles act as "change agents" within the conifer forests of the Rocky Mountains, affecting the ecosystems directly and indirectly. Direct effects include individual tree death, changes in forest stand densities, changes in coarse woody debris, changes in forest floor litter, and changes in the amount of light reaching the forest floor. Indirect effects include timing, scale, and intensity of fire, changes in water quality and quantity, changes in wildlife use of the forest, changes in species composition, age, and size of remaining trees, and changes in commodity and/or amenity values. The effects can be grouped into three major areas: biological, nonbiological, and human-use effects.

\section{Biological Effects}

Native bark beetle populations affect forest ecosystems most significantly through tree killing. The role of bark beetle outbreaks in ecosystem dynamics depends on the habitat type and host tree species composition. The interaction between fire and bark beetle outbreaks is also an important factor that must be considered. Different outcomes in terms of stand and site conditions and future susceptibility to bark beetles will occur depending on the presence, scale, and intensity of fire following a bark beetle episode. The following describes bark beetle effects on forest ecosystems by host tree species.

Lodgepole Pine. Mountain pine beetle is the primary bark beetle affecting lodgepole pine in the Rocky Mountain area. During the endemic phase, individual trees are typically killed, resulting in patchy mortality throughout the stand (Figure 8). Given the right conditions of susceptible tree size, age, and density (average diameter, 8 inches or more; 80 years old; and a stand basal area of 120 square feet or greater), beetle populations may reach the outbreak phase, in which 80 percent or more of an even-aged, homogeneous pine stand can be killed over a 5 to 7 year period (Figure 9). Mountain pine beetle epidemics, for example, are capable of killing in excess of 100 trees per acre, per year, in susceptible lodgepole pine stands over the course of a 3 to 4 year outbreak.

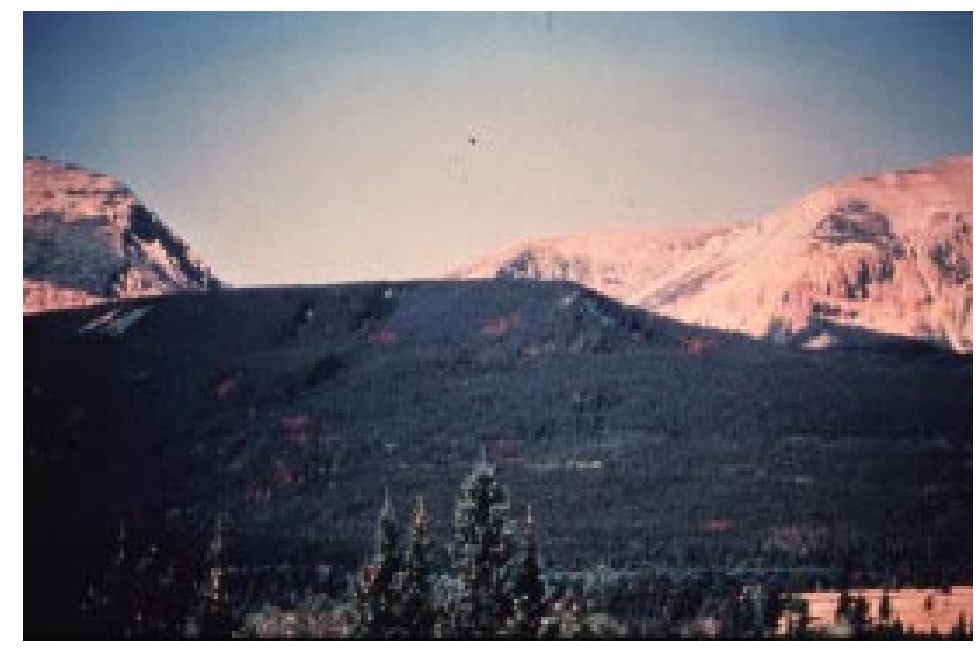

Figure 8. Patch mortality in lodgepole pine due to mountain pine beetle. 


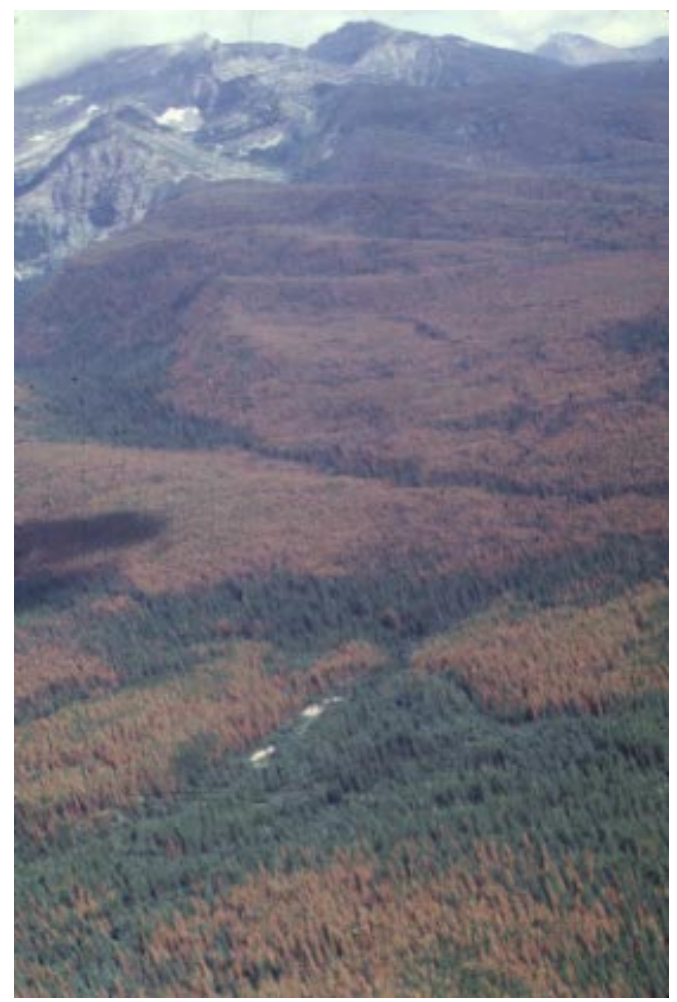

Figure 9. Mortality in lodgepole pine forest in Glacier National Park.

Population outbreaks in lodgepole pine are often stand-replacing events, as fire usually follows the outbreak within 15 years. Because lodgepole pine cones require heat to open, the fire provides the necessary conditions for stand regeneration back to lodgepole pine. If a fire does not occur following an outbreak, the major reductions in stand density will release the understory trees, which are most often other species, allowing them to assert dominance of the stand. For example, in the absence of fire, a lodgepole pine stand would eventually shift to a spruce and fir stand.

Ponderosa Pine. Although mountain pine beetle is one of the major bark beetles affecting ponderosa pine, western pine beetle, Ips beetles, and the roundheaded beetle (in the southern portion of the region) are also responsible for ponderosa pine mortality.

Endemic beetle populations have minimal effects on stands, killing individual and occasionally small groups of trees. If populations build to outbreak levels, 40 to 60 percent of the stand can be killed, depending on the age and size classes within the stand. Historically, endemic populations and low-level outbreaks have provided the fuel necessary for the periodic low-intensity fires that help perpetuate uneven-aged ponderosa pine stands. However, with the exclusion of fire, stand densities increase and age-class diversity decreases, making these stands more susceptible to beetle population outbreaks. When a large-scale outbreak does occur, fuel loads will increase, leading to large-scale crown fires and replacement of tree cover with grasses and shrubs. In mixed-species stands, a population outbreak without a subsequent fire would reduce or eliminate the ponderosa pine component of the stand, moving the stand towards a fir or spruce cover type. 
Spruce. The ecological role of Engelmann spruce will change depending on characteristics of the site it is inhabiting. Spruce is typically considered a late successional species, often codominant with fir. However, in portions of the Rocky Mountain area with higher levels of summer precipitation, spruce may play the pioneering role on a site. Even-aged spruce stands are an example of this. More common, however, are mixed-species stands with an uneven-aged distribution of spruce.

Spruce regeneration requires some low level of disturbance, as well as shade and moisture. An example of a disturbance that facilitates spruce regeneration is the spruce beetle. Spruce beetle populations are typically found at endemic levels, infesting downed spruce scattered throughout the forest.

However, increases in downed material due to wind events or logging slash, for example, provide the opportunity for beetle populations to increase rapidly. Where these types of disturbance occur, large numbers of spruce can be killed. In spruce stands on the Manti-La Sal National Forest in southern Utah (covering about 20,000 acres), 73 percent of the spruce trees greater than 5 inches in diameter were killed over a period of about 5 to 7 years, with a 47 percent decline in the spruce component. Figure 10 graphs the effects of spruce beetle on tree proportions within the infested area on the Manti-La Sal National Forest. The younger spruce trees that are not killed by the spruce beetle and nonhost trees (such as firs) will provide shade for spruce regeneration in such situations. If a large fire were to occur, spruce regeneration in the stand would follow regeneration of a pioneer species, such as lodgepole pine or Douglas fir at low elevations, and aspen and subalpine fir at higher elevations.

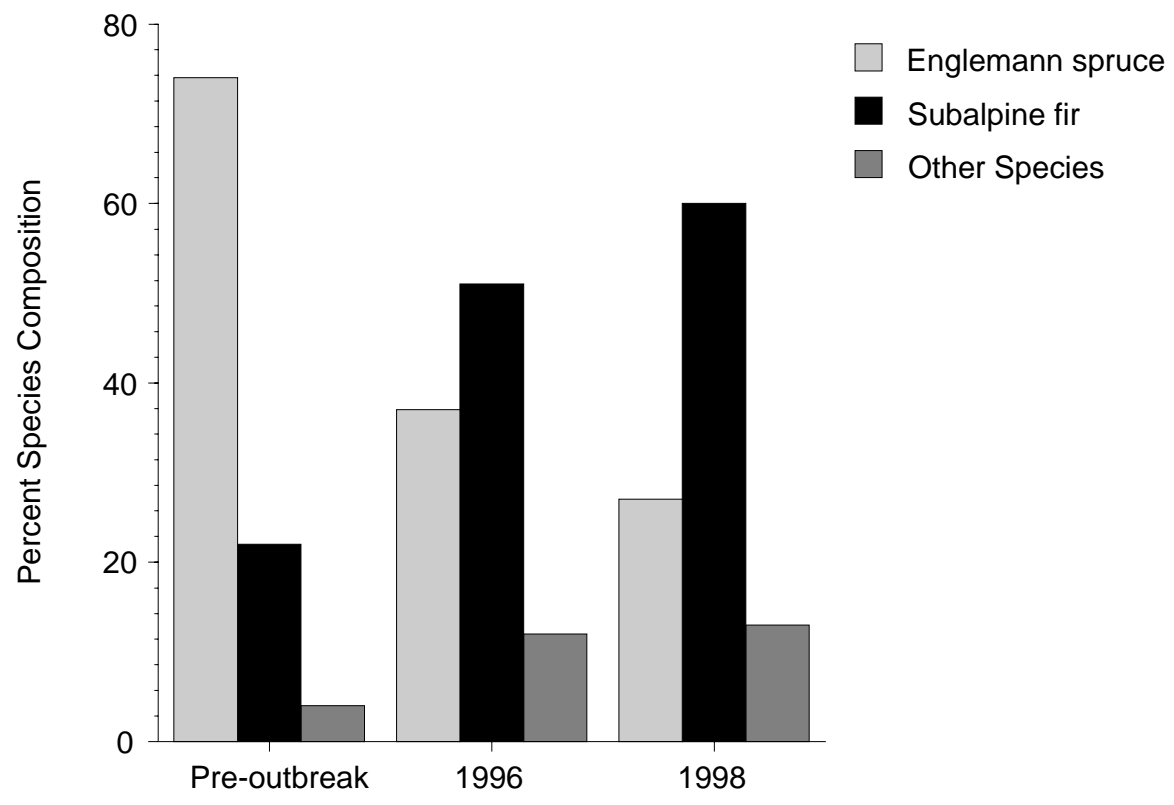

Figure 10. Percentage of spruce in the spruce beetle-infested area of the Wasatch Plateau on the Manti-La Sal National Forest in central Utah before and after a spruce beetle outbreak. 
Douglas-fir. Historically, this species was found growing among other tree species, such as Engelmann spruce, western larch, ponderosa pine, western white pine, and lodgepole pine, with fire maintaining the balance among the species. Because Douglas-fir did not occur in large, homogeneous stands, outbreaks by Douglas-fir beetle were typically not widespread across a landscape, although 40 to 60 percent of the Douglas-fir within a stand could be killed. Fire exclusion, along with selective logging and the introduction of white pine blister rust (a lethal fungus that attacks white pine), have changed the species diversity of many forests in Idaho. Douglas-fir is currently twice as prevalent in stands that historically contained a mixture of western white pine, larch, ponderosa, and Douglas-fir (Figure 11). The severity of the current Douglas-fir beetle outbreak in this landscape is more catastrophic than pre-Euro-American trends due to the abundance, distribution, and age of the current Douglas-fir stands.

\section{Changes in Forest Cover Type Idaho Panhandle National Forest}

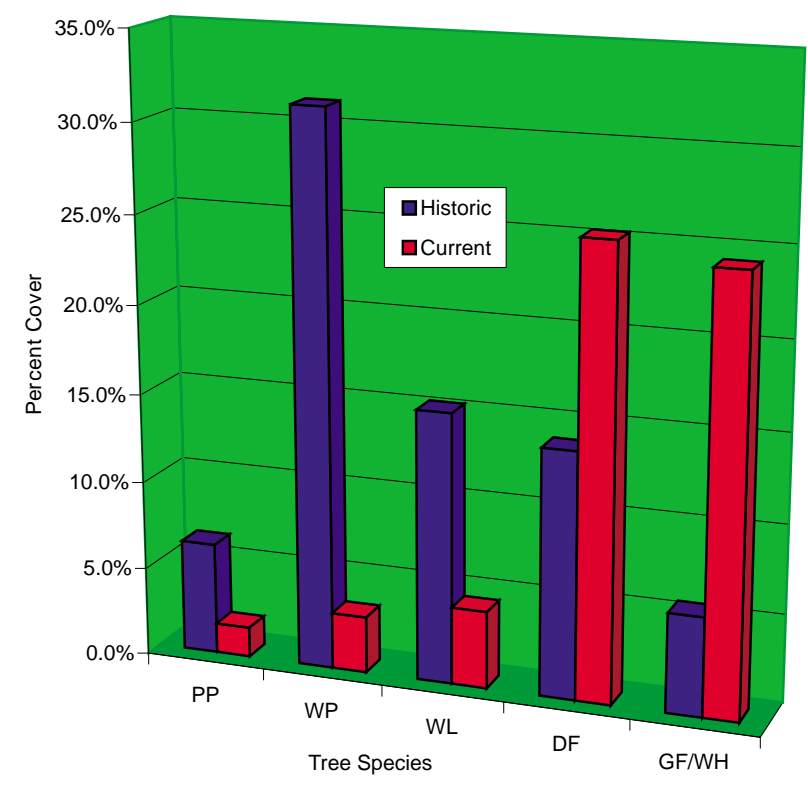

PP (ponderosa pine); WP (western white pine); WL (western larch); DF (Douglas-fir); GF/WH (grand fir/western hemlock)

Figure 11. Changes in forest cover type in the Idaho Panhandle National Forest.

Understory Vegetation. Canopy gaps created by the death of bark beetle-killed trees allow light to reach the forest floor, creating opportunities for an array of herbaceous species. In some regions, exotic weed species may invade the forest floor following a bark beetle outbreak and subsequent fire. These exotic weeds are then highly capable of out-competing the native understory vegetation, reducing biodiversity in the understory.

Wildlife. Bark beetle populations and their effects are important to several wildlife species, including threatened and endangered species. For example, woodpecker species (three-toed, hairy, black-backed, downy, white-headed, and pileated woodpeckers) use bark beetle larvae as a primary food source. Bark beetle-killed trees also provide nesting and roosting trees for many woodland bird species. 
Low levels of mortality in riparian areas due to bark beetles can provide necessary woody debris input for many aquatic species. Conversely, outbreaks that contribute to abundant mortality may cause increases in sediment load in streams and increased temperatures detrimental to many aquatic species, including trout.

Northern goshawk populations require at least 40 percent of a landscape in mature and oldgrowth forests. These same forest types are also preferred by many bark beetle species. Other species, such as lynx, also have habitat requirements (windthrow) that overlap with conditions suitable for bark beetle population outbreaks. The resulting conflict is a dilemma for forest managers.

\section{Nonbiological Effects}

Effects of bark beetle outbreak include other environmental change. These are described below.

Water. Reductions in live tree densities due to bark beetle mortality can increase runoff due to decreased transpiration and less interception of snow and water by foliage. Stand-level mortality rates of 20 percent or greater are required before additional water yields are noticeable. Increased runoff can increase rates of soil erosion and streambank instability due to greater instream flows. Postoutbreak wildfires can affect water quality as subsequent erosion deposits ash and soot into streams, changing water chemistry.

Soils. Beetle-caused tree mortality has direct and indirect effects on soils in the damaged area. Direct effects include increases in litter from needle-fall, corresponding increases in bulk density, organic material, and water-holding capacity. Indirect effects include those stemming from wildfire after an outbreak, such as increased bulk density due to baking of the soil, consumption of organic material, and loss of minerals due to volatilization.

\section{Human-Use Effects}

A bark beetle outbreak can affect human use and enjoyment of America's forests. These assets include residential and administrative sites, high-use developed recreation sites, and areas valued for their scenic beauty.

A bark beetle outbreak can change the structure, species composition, and appearance of forest landscapes and particular sites in ways both detrimental and beneficial to short-term human use and long-term management goals. The damaging effects associated with a bark beetle outbreak include the lowering of property and timber values, degradation of various activities (including recreation), and loss of aesthetic or scenic beauty of landscapes. These effects are of comparatively short duration, but obvious. Long-term positive effects evolve more slowly and may go unnoticed. These include the social, cultural, and ecological importance of proper forest functioning, such as maintaining biodiversity, sustaining natural processes, and providing historic cultural identity.

The overall magnitude of the damages incurred as the result of bark beetles varies according to the different land-use designations and human expectations for what these areas provide. A given level of insect damage can significantly diminish human enjoyment in some areas but have little or even positive effects in others. This overall effect on human use and enjoyment depends on the characteristics of an area, the number of users, and expectations of users. 
Wildland/Urban Interface. Increased fuel loads that accompany most outbreaks put homes, businesses, and other structures in the wildland/urban interface at risk of damage or loss in both management (prescribed fires) and wildland fires, and risk of injury and death for residents and firefighters alike. Postoutbreak fuels management costs are significantly higher and more complex due to intermingled ownerships and the inherently high risks associated with tools such as prescribed fire.

Beetle infestations that kill or cause visible damage to trees near residential mountain properties can reduce aesthetic and property value. Bark beetle impacts are significant in the urban and wildland/urban interface areas because of the effect on property values and risk of fires. Beetle infestations may be considered most destructive in residential areas where the worth of trees for amenity benefits greatly exceeds values associated with wood products.

Not only is there loss of value to property owners, but there is the cost of removing dead trees. Nearly all of the trees that die or are fading within the development zone are destined to become hazards and will eventually have to be removed. The property owner can be faced with complicated and possibly costly tree removals in the area where structures are densely packed and interwoven with dead trees.

Recreation. Recreational values are impacted by bark beetle outbreaks through the direct effects of tree mortality and indirectly through increased fuel loading and a subsequent increase in fire potential. The effect of bark beetle outbreak damage on developed recreation sites (campgrounds, summer homes, organization camps, visitor centers, view points, and other places of concentrated human use) would likely be more severe than in areas where recreation is dispersed over larger areas. Recreation sites are likely to be negatively affected in the short term by outbreaks of bark beetles. Nevertheless, long-term effects on these values may be positively impacted through enhanced ecosystem functioning.

Large-scale outbreaks have short-term effects on recreational use of wilderness areas, particularly in regard to scenic quality, trail access, and public safety Loss of tree cover from beetle mortality, hazards to the public from falling trees, significant changes in scenic values and risks to facilities, structures, and the public from subsequent fire are all short-term effects of beetle outbreaks. In ski areas, loss of overstory cover affects snow retention due to an increase in winds that move snow and the absence of shading (Figure 12).
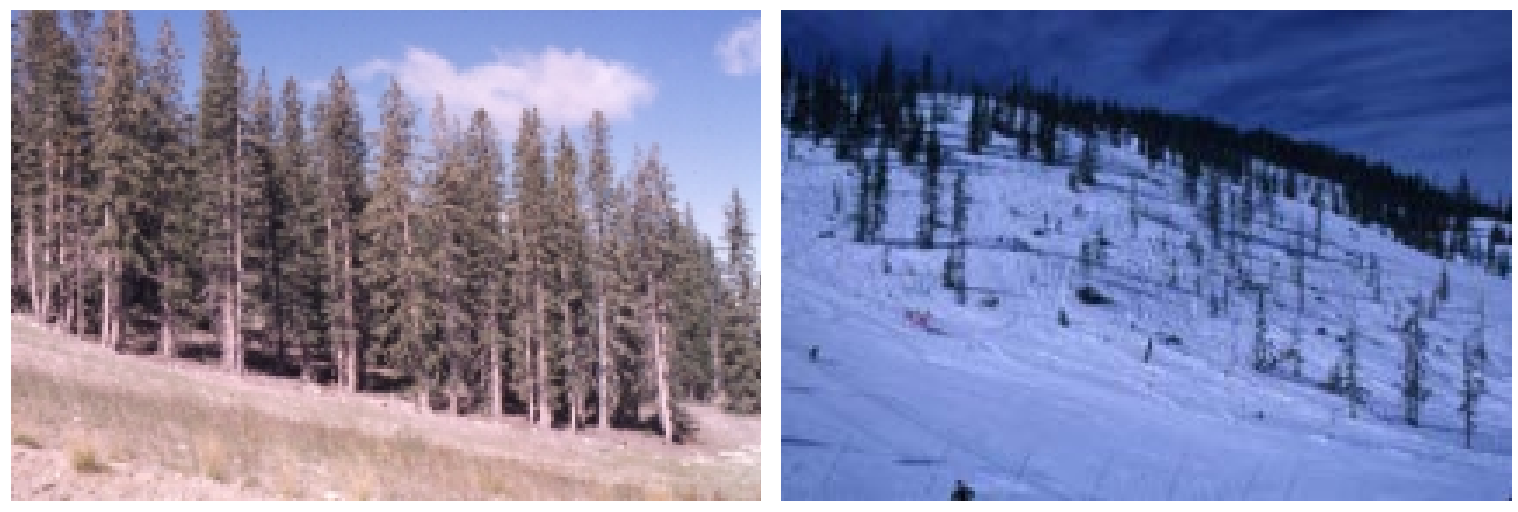

Figure 12. The Brianhead Ski Resort, before and after bark beetle outbreak, Dixie National Forest, Utah. 
Scenic Values. Beetle-caused mortality can have major effects on visual quality, especially where mortality exceeds 50 percent. During and following a large outbreak, areas with high scenic values such as parks, resorts, recreation areas and the wildland/urban interface can experience reductions in scenic quality for 10 years or more. Bark beetle outbreaks and effects on visual quality can be observed in Cedar Breaks National Monument in Utah, Vail in Colorado, Yellowstone National Park in Wyoming, and Glacier National Park in Montana.

Economic Values. Loss of commodity value due to bark beetle infestation in those areas where commodity production is a resource management objective can be significant. Beetle-killed trees have a limited time frame for use as structural products (less than 5 years) due to wood decay. Dead trees are generally worth only about a third of the value of green trees of the same species as structural quality is reduced. In some cases, beetle-killed trees provide a specialty product, such as $\log$ for log homes, which are worth more than if the trees were green.

Management costs are increased by bark beetle outbreaks for virtually all resources. Trail maintenance costs are increased due to additional deadfall (Figure 13); recreation area management is increased due to high-value individual tree protection, hazard-tree reduction, fire protection, and reduction in use fees; road maintenance costs are increased due to deadfall and hazard tree removal; utility maintenance costs are increased due to trees falling on utility lines; and homeowners experience loss of value through death of landscape trees, degraded views, and dead trees falling on improvements. Suppression treatments and beetle population monitoring costs are also incurred.

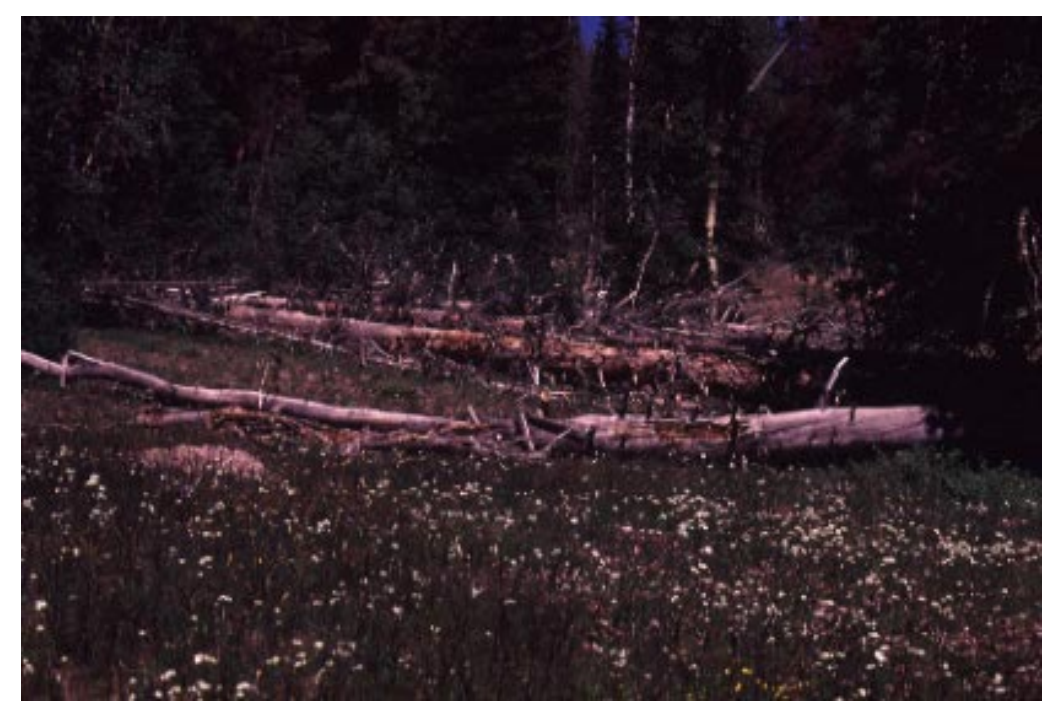

Figure 13. Deadfall on a trail, Dixie National Forest, Utah. 


\section{BARK BEETLE MANAGEMENT OPTIONS}

In reviewing reports of bark beetle activity throughout the Rocky Mountain area, a common perception is that all outbreaks cause a loss of commodities and therefore need a "solution" to end the problem. However, the labeling of bark beetles as pests and dead trees as losses depends primarily on management objectives. If the desire is to maximize returns or protect a resource, mortality due to bark beetles may indeed be counted as a loss in need of a solution. When considered as part of ecological processes, bark beetle-caused tree mortality may be more acceptable to stakeholders.

For many objectives, tree mortality caused by bark beetles will be judged as a financial loss. Traditionally, bark beetle management activities have ranged from no action to active prevention and suppression, with the emphasis on suppression (control the beetle and deal with tree mortality after the damage has occurred). However, the old saying that "An ounce of prevention is worth a pound of cure" is especially valid when dealing with bark beetles. Preventing damage is generally less disruptive to planned activities and objectives and, in the long run, costs less than reacting to outbreaks with suppression efforts.

In many areas, stand conditions are out of balance due to fire suppression, harvesting, and other activities. Because of this imbalance, we need to manage bark beetle populations more actively than we have in the past. Both prevention and suppression strategies may be required for a successful bark beetle management strategy, and the tactics used will be specific to the particular site and situation.

Strategies for bark beetles management generally fall into three categories:

- Long-term (greater than 20 years) prevention techniques that use silvicultural actions and prescribed fire to reduce stand susceptibility to bark beetle outbreaks.

- Direct control or suppression treatments that reduce beetle populations to address shortterm needs.

- Restoration of the functional role that bark beetles play in maintaining the system's ecological integrity and sustainability.

An assessment of the current situation precedes any strategic planning or active treatment. A variety of treatments are then available to manage bark beetle populations. Some may be applied singly; others, appropriate in an integrated approach using a combination of treatments. Each situation requires an evaluation to determine the best treatment approach, tiered to ecological and socio/economic factors.

Silvicultural techniques can be used or developed to produce stand structures and landscapes that reflect the complexity of natural forests. These techniques include the use of long harvest rotations, stand structural retention, and stand structural restoration. Structural retention involves measures to retain significant structural elements (e.g., large, old, decadent trees and snags) as a basis for the succeeding forest components. Restoration involves measures to speed up the development of structural complexity in a young stand. These measures include the use of thinning by fire to create multistoried stands with multiple species. 


\section{Assessment}

Assessments are required across all ownerships to determine landscape or stand susceptibility to bark beetle population increases and the current level of bark beetle activity. Stand and landscape susceptibility/risk rating systems have or are being developed to assess forest susceptibility to bark beetle attack. To estimate bark beetle populations and trends, entomologists use data obtained from aerial surveys, attractant pheromones placed in traps, and individual tree-sampling techniques. Aerial and ground surveys are used to collect these data, which enable the resource manager or landowner to develop a treatment strategy that could include prevention, suppression, and restoration activities (Figure 14).

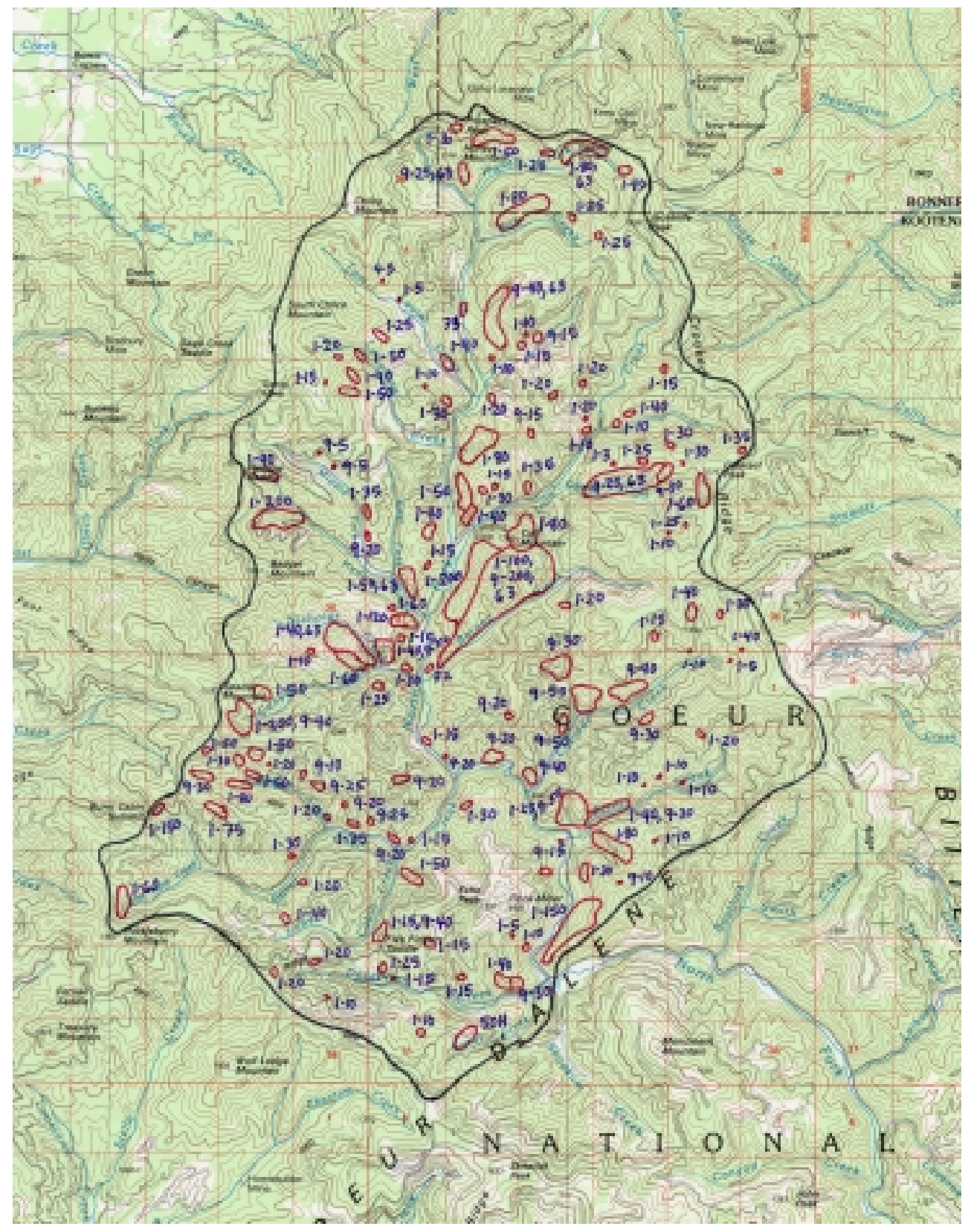

Figure 14. An aerial sketchmap of tree damage and mortality. 


\section{Prevention}

Prevention is a pro-active approach designed to change conditions that are conducive to successful bark beetle attacks and development. Prevention is best accomplished by reducing available food sources and modifying the stand environment. Generally this is accomplished by implementing silvicultural practices that decrease tree and stand susceptibility. Timely removal of wind thrown trees that are favorable sites for bark beetle brood production, is an important approach that can be used to minimize bark beetle population increases. If infested trees are not removed or destroyed, adults can emerge and attack surrounding green trees.

The ability to be pro-active using preventive techniques is important in a bark beetle management strategy. Prevention strategies are implemented before an outbreak occurs and often address stand susceptibility across larger landscapes. Characteristics associated with prevention strategies take the following factors into consideration:

- Prevention treatments can create vegetative mosaics.

- Prevention treatments can be beneficial to adjacent sites where either management activities are not permitted or where they are not appropriate.

- Prevention treatments can use wild and prescribed fire as a management tool.

- Prevention treatments can provide more resilient effects than suppressive treatments.

- Prevention treatments can reduce the risk of widespread and abundant tree mortality.

Prevention strategies are generally long-term treatments that require multiple entries into a stand, resulting in years of reduced stand susceptibility to bark beetle outbreaks.

\section{SUPPRESSION}

In contrast to prevention, suppression strategies only address established bark beetle populations and are often associated with suppressing developing populations. Characteristics of suppression activities take the following factors into consideration:

- Benefits are usually short-term.

- Suppression treatments generally occur at smaller scales.

- Activities respond to developing or outbreak populations of bark beetles.

- Large-scale vegetative changes may have already occurred that alter or adversely affect resource objectives before the suppression treatment is initiated.

- There is a limited set of alternatives designed to respond to crisis.

- Suppression treatment can be a one-time response.

- Suppression strategies may protect economic resources.

- Outbreaks are visually apparent, which may generate public support for treatments.

Suppression activities use various techniques, including salvage cuts (cutting live and dying trees to capture economic gain) and sanitation cuts (cutting diseased or attacked trees) to remove the beetles from the area, pheromone traps and trap trees to capture the beetles, or pesticide treatments. Suppression activities are generally short-term strategies that do not modify the stand environment or change stand characteristics that allow the beetle populations to increase. Suppression strategies often require repeated application over several years. However, suppression activities, when implemented early in an outbreak, can reduce the rate of spread and suppress the bark beetle 
population. These short-term suppression strategies are effective and provide the resource manager with time to design prevention treatments that address the cause of the outbreak.

\section{RESTORATION}

The goal of ecological restoration is to reestablish the system's ecological integrity-the degree to which the ecosystem's components and their relationships are present, functioning, and capable of self-renewal. Restoring the ecological functionality of bark beetles is a management approach that attempts to maintain the ecological benefits of active bark beetle populations and at the same time maintain beetle populations within acceptable limits. As previously discussed, many forests today have increased stand densities and altered species composition. As a consequence, bark beetle outbreaks in these altered ecosystems are probably more catastrophic (with respect to increased extent and intensity) than those that previously occurred. By understanding the host forest condition that maintained spatially distributed pockets of mortality, restoration techniques (primarily applying silvicultural manipulation and fire) can be used to reestablish the resiliency of these systems to a host of disturbances including bark beetle outbreaks.

\section{Tools}

The following are management tools that can be used to address forest health concerns related to bark beetles. They can be used separately or in combination, according to the demands of the situation. Because there are several ways to achieve an ultimate goal, no single treatment or combination of treatments is an exclusive response to a given situation, ensuring flexibility and responsiveness.

\section{The No-Action Option}

As implied, the "no-action" option intentionally allows an outbreak to run its course. This strategy may be appropriate where abundant tree mortality is acceptable, effective treatments are not available or infeasible, or in certain land use areas, such as Forest Service-designated wilderness or similar management units. Implementation of this strategy is not without consequences, particularly after a century of fire exclusion and other vegetative changes throughout the Rocky Mountain area. As described previously in this document, forest conditions have changed significantly over the last 200 years. Forests in the Rocky Mountain area are generally older, more homogenous, and have greater densities as a result of previous management tactics. The effects of bark beetle outbreaks within these forest communities are often severe. Under a "no-action" approach, forests that become more homogenous are more susceptible to bark beetle outbreaks that will cause extensive tree mortality across larger landscapes. However, following a large-scale outbreak, managers may have the opportunity to return the landscape to one that is less susceptible to future outbreaks.

\section{Thinning}

There is general consensus that susceptibility of trees to attack by bark beetles is related to tree vigor, stand environment, and stand attributes (i.e., age, size, and composition) conducive to bark beetle population increases. Studies conducted with mountain pine beetle in lodgepole and ponderosa pine indicate that thinning treatments (selective tree removal) modify the stand 
environment and eventually increase residual tree vigor. This preventive approach reduces stand susceptibility to attacks by mountain pine beetle.

Reducing the number of trees in a given area increases the amounts of water, nutrients, and light available for remaining trees. Thinning can change species composition and aspects of the physical environment including light, temperature, and air movement. The combined effect of thinning treatments is reduced tree and stand susceptibility to bark beetle attack. Stands that have been thinned will normally require additional treatments as tree growth and density increase through time. Also, timing of treatments is critical to avoid an increase in bark beetle populations that utilize slash (stems left on the ground) and could subsequently cause mortality of the residual trees.

\section{Fire}

In fire-adapted ecosystems of the Rocky Mountain area, maintaining bark beetle activity at endemic levels to meet resource objectives requires the use of fire and other forms of disturbance. Fire is also an important component of ecological restoration for treatment of fuels and maintenance of stand density and species composition. Fire used as a management tool must be similar to the integrated role that fire played within each type of ecosystem. This type of disturbance can be used as a prevention strategy: either prescribed wildfires where wildfires are left to burn under carefully monitored conditions, or managed fires where we initiate the fire event. This prevention strategy may be the most appropriate tool in areas that exclude motorized access and/or tree harvest.

There are situations in which stand conditions have changed to the extent that introducing fire would pose a significant risk. In these instances, mechanical treatments are required to reduce the amount of accumulated vegetation or its arrangement within the landscape. Mechanical treatments and fire can be combined in a prevention strategy to reduce risk of bark beetle outbreaks. The fire option cannot be viewed as a single treatment, but as a recurring treatment to maintain or restore desired vegetative conditions.

\section{Salvage and Sanitation}

The goal of salvage operations is to remove dead, damaged, or dying trees in order to recover economic value that would be otherwise lost. Sanitation cuts remove trees to improve stand health by stopping the actual or anticipated spread of insects and disease. These two treatments are often mentioned together as their target trees can overlap.

Removal of dead and beetle infested trees is a treatment that helps to reduce local beetle populations and prevent further mortality in the area. Timing is critical since treatment activities must take place before adult beetle flight occurs and the insect spreads to different sites.

\section{Regulation of Stand Composition}

Many stands of the Rocky Mountain area are composed of species that have increased in density or acreage due to past management practices. Harvesting of seral species (species that occur early in the natural temporal progression of tree species on a site) without provision for their replacement and fire exclusion practices are two primary reasons for this increase. Both practices contribute to changes in stand composition that promote climax species (naturally occurring species that ultimately dominate a site). In many instances, these stands are now decadent, in poor health 
and succumbing to the effects of forest insects and diseases, including bark beetles. One example is in northern Idaho, where Douglas-fir has approximately doubled compared to densities observed 80 to 100 years ago (Figure 11, page 15). This area recently experienced a large outbreak of Douglasfir bark beetles. The severity of the current Douglas-fir beetle outbreak in this landscape has proven to be much more catastrophic than historic trends indicate because host species within the system are not part of the historic sequence of species on the site. Where appropriate, silvicultural practices that restore seral species will contribute significantly to the species diversity that occurred previously. These practices may include clearcutting, shelterwood cuts, and seed-tree cuts described previously.

At times, the best alternative to meet long-term forest health objectives is to initiate a stand replacement strategy through "regeneration harvest." When management objectives require a vigorously growing forest, removing some stagnated old growth may be the best option. In many forests of the Rocky Mountain region, existing stands are composed of shade-tolerant species that have replaced seral species, often as a result of fire exclusion. Often, these species are susceptible to root diseases or other debilitating agents. Regeneration harvests involving clearcutting (removing all trees), shelterwood cuts (removing all but the most healthy, vigorous trees to provide protection for other emerging understory trees) or seed tree cuts (removing all but the most healthy, vigorous trees to reproduce) provide opportunities to convert forest stands to seral species, increasing overall tree vigor and forest health. This management alternative can be used to create a mosaic of stand conditions from large, susceptible host types to less susceptible landscapes composed of a variety of ages, sizes, and species mixes.

\section{Pheromone Use}

Semiochemicals (message-bearing chemicals), emitted by both the attacking beetle and the host tree, affect beetle behavior during aggregation and mating. Certain elements of beetleproduced semiochemicals, called pheromones, when combined with specific host odors, guide dispersed beetles to a targeted tree. This ensures that the beetles attack in sufficient numbers to overcome the defenses of the tree.

These attractive elements have been artificially synthesized and are commercially available as lures specific to individual species of bark beetles. The lures are effective attractants that serve to concentrate attacking adult beetles on suitable host trees or pheromone traps (Figure 15). Concentrated beetle populations within the baited host tree are either removed or destroyed, while pheromone traps are used to capture flying beetles. Both techniques have been used operationally in sanitation and salvage programs to suppress localized populations of bark beetles. The aggregation pheromones have also been used to monitor beetle populations and flight periodicity (timing). This information is used by resource specialists to time appropriate treatment activities and to document beetle population pressure and activity within the monitored area.

There are also chemicals that serve to disrupt aggregation behavior, driving beetles away. These antiaggregation compounds are used to divert dispersing adult beetles to other sites. Methylcyclohexenone (MCH), an antiaggregation pheromone for Douglas-fir beetle, has been used successfully to protect high-value sites. Use of synthetic pheromones to monitor, suppress and repel beetle populations has been an effective management strategy for a variety of bark beetle species. Unfortunately, synthetic pheromone lures do not exist for all bark beetle species in the Rocky Mountain area. Only the antiaggregation pheromone $(\mathrm{MCH})$ for Douglas-fir beetle has been used with any operational success. The biological role of antiaggregant pheromones in the behavioral ecology of bark beetle species remains unclear. 


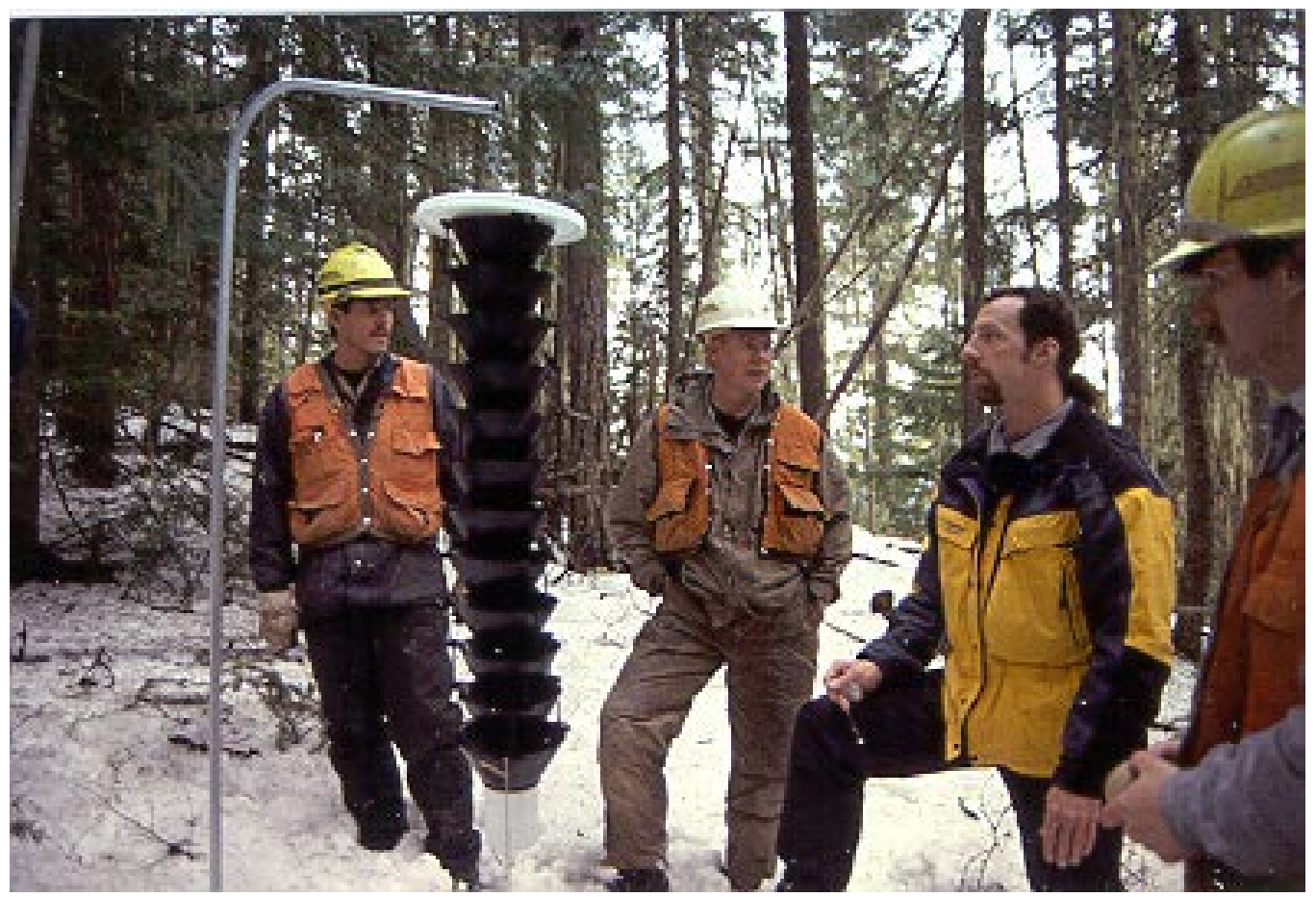

Figure 15. Pheromone-baited funnel trap.

\section{Trap Trees}

Trap trees are downed or pheromone-baited trees used to attract flying beetles from living standing trees to suppress localized populations of Douglas-fir and spruce beetles. This technique is often used with other bark beetle suppression tactics, including sanitation, salvage, and pheromone traps. Trap trees are living, larger diameter (greater than 14 inches) trees that are felled, or left standing and baited with an aggregation pheromone to attract dispersing adult beetles. Adjacent susceptible hosts are also often attacked as a result of the trap tree strategy and become part of the "trap."

The aggregation pheromones released by the adult beetles will attract other adult beetles to the attacked trees. Once the trap tree is infested, they and all other adjacent infested trees must be removed or destroyed on site. Trap trees effectively attract beetles from up to a quarter of a mile, though their effectiveness decreases as this distance increases.

For spruce beetle and Douglas-fir beetle, the optimum trap-tree approach uses felled green trees. In every case, this technique of attracting dispersing adult beetles is only effective if all the infested trees are removed or destroyed. Aggregation pheromones applied to standing trap trees should only be used under the direction of a forest entomologist who is familiar with pheromone applications. Used incorrectly, they can contribute to increased beetle populations and additional tree mortality.

\section{Insecticides}

Protective insecticide sprays have been used extensively to protect individual trees (Figure 16). The material must be applied before the tree is infested as bark beetles tunnel under the 
bark, making them inaccessible to the spray. There are protective sprays available for all three bark beetle species highlighted in this report. These insecticides are often restricted for use on highvalue urban trees and trees in recreation area due to cost and accessibility. This type of treatment is often expensive and may require multiple applications to protect high-value individual trees.

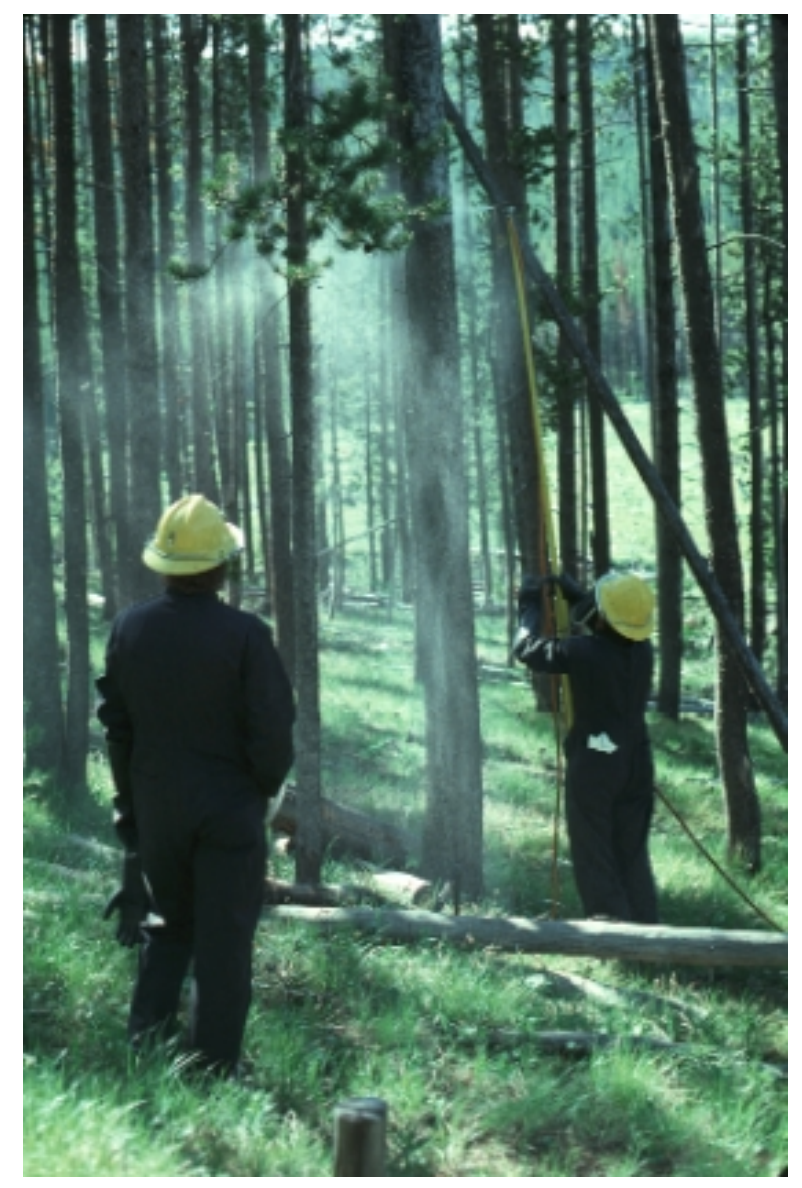

Figure 16. Spraying trees on the Black Canyon Loop Road in the Targhee National Forest, southeastern Idaho.

\section{Other Treatments}

There are other treatments used on a limited basis in high-use areas (such as wildland/ urban interface and recreation areas) to reduce bark beetle populations. These treatments include solar treatments, burning or burying the infested material, peeling the bark, or partially submerging the tree in water. Some of these treatments, like burning or burying the infested material or removing the bark, are effective but extremely labor intensive and expensive. Solar treatments, including cutting infested material into smaller pieces (less than 16 inches in length) and either exposing the surfaces to direct sun or covering the material with plastic (to raise the temperature and dry the wood), have had mixed results. Partially submerging infested material in water has been used near sawmills, but the broods are often not entirely destroyed, particularly if the adult beetles are already prepared to emerge from infested logs and disperse to other sites. 


\section{CASE STUDIES}

We include here several examples of projects that were enacted or are currently under way to further illustrate the various options for bark beetle management and the treatments that can be used to achieve management objectives. As we have noted, the actual treatments and tactics used are not unique to a specific management objective. The case histories included here span the range of management objectives from active suppression to no action.

\section{Spruce Beetle on Federal and State Lands in the Payette Lake Area of West-Central IDAHo}

The hazard posed by spruce beetles following wind throw of large-diameter spruce is recognized and well documented. During the winter of 1981 to 1982, many scattered areas of Englemann spruce were blown down throughout the Payette National Forest and on adjacent state and private lands. Few spruce beetle attacks were noted in 1982, but from 1983 to 1993, over 384,000 beetle-killed trees were recorded during aerial detection surveys. This mortality was primarily on National Forest lands. A decision was made in 1986 to salvage wind thrown trees and place trap trees throughout the area in an effort to contain the infestation. Problems occurred with trap tree removal and a loss of timber value, and many infested trees were left in the area, allowing the beetles to emerge and attack more trees in the vicinity. By late 1986, forest managers realized that the magnitude of the infestation was beyond their ability to control. In 1989, a new environmental assessment was proposed to accelerate harvest of live trees to capture economic value before attack by spruce beetles. This project was repeatedly delayed, and the number of infested trees continued to increase. Peak mortality on National Forest lands occurred in 1990, when 185,460 dead trees were recorded in the aerial survey. Throughout the area, 77 to 95 percent of spruce larger than 12 inches diameter at breast height (DBH at 4.5 feet above ground level) were killed.

On neighboring state lands, the outbreak was dealt with in a more aggressive manner to meet the management objectives of the State of Idaho. In 1890, the Idaho Admission Bill formally declared the existence of the State of Idaho, granting to the new State the equivalent of 2 of every 36 square miles of Federally owned land within its borders. These lands were designated as "school lands," with the requirement that they be managed exclusively for the support of public schools. Other provisions of the admissions bill authorized grants of additional land for the support of other public beneficiaries, including the State university and State hospitals. The State constitution mandates that these endowment lands be managed "...in such a manner to secure the maximum long-term financial return to the institution to which they were granted."

In keeping with the mandates of this management policy, the State was aggressive in avoiding loss of commodities, which would result in a loss of income to the various endowments. The decision was made to aggressively salvage windthrown and standing beetle infested and killed spruce and to conduct additional harvesting of susceptible high-risk live trees in the area prior to beetle attack. Sales were prepared and sold in a timely manner to capture higher timber values associated with recently attacked (versus dead) trees and to sell uninfested trees at yet higher prices. This course of action maximized income for the endowments while minimizing spruce beetle caused losses. This approach complied with the management directive for the endowment lands. 
Due to differences in management objectives and governing laws and regulations, the State of Idaho was able to recover the economic value of beetle-killed trees while a great proportion of that value was lost on National Forest System lands.

\section{Bark Beetle Recovery Project on the Dixie National Forest in SOUTHERN UTAH}

This is an example of both suppression and prevention management strategies in the urban/ wildland interface. In response to a 1992 Congressional hearing on forest health, the 1987 Forest Health Strategic Plan, "Forest Health Through Silviculture and Integrated Pest Management: A Strategic Plan," was modified. The new plan included a Western Forest Health Initiative with three priorities: (1) reduce the hazard of catastrophic loss in key ecosystem structure, composition, and processes; (2) restore critical ecosystem processes; and (3) restore stressed sites.

This project was designated a "Priority 1" project to reduce the hazard and loss of ponderosa pine caused by outbreak populations of mountain pine beetle. The project area encompassed intermingled Federal and non-Federal lands near a resort community and several summer home areas. The project ran from 1994 to1996 and encompassed approximately 3,000 acres within and adjacent to mountain pine beetle-impacted areas. Project cooperators included:

- Utah Division of Forestry, Fire and State Lands

- USDA Forest Service - Forest Health Protection

- USDA Forest Service - Dixie National Forest

- Mike Kenner, Mountain Services

- Pesticide application companies

- Homeowner associations

The project was designed to:

- Evaluate susceptible sites on nonindustrial private land.

- Facilitate treatment of trees considered high risk and high value.

- Reduce long-term risk by recommending appropriate preventive treatments.

- Develop a salvage program for subdivisions to remove dead and infested host trees.

- Develop an educational program designed to inform the public about the biology and behavior of the insects, potential effects, and prevention/suppression treatment alternatives.

- Describe stand structure and density management guidelines to meet landowner objectives that emphasize forest health, ecosystem function, and a reduction in wildfire hazards.

- Develop a Forest Stewardship Plan for the community of Duck Creek Village.

A large landowner base distributed literature and later contacted involved parties to coordinate treatments. State and Federal officials assisted with assessing risk, developing treatment alternatives, mapping treatment sites, securing bids for treatments, administering contracts, and allocating treatment costs to landowners. Federal and State officials coordinated treatment efforts to lower costs, improve efficiency, and ensure the effectiveness of selected treatments. Suppression treatments consisted of removing dead and infested host trees, preventative insecticide applications, 
and treatments that reduced downed and standing material that contributed to an increase in forest fuels for fire. Defensible fuel breaks were also established around some of the communities where bark beetle-caused tree mortality contributed to fire risk. Insecticide applicators were trained by Federal and State personnel to ensure that only uninfested susceptible hosts were selected for treatment. Training also included correct application procedures to improve treatment effectiveness. Private landowners also received recommendations that would improve vegetative diversity on their lots.

This cooperative approach between Federal and State officials working in conjunction with private homeowners to address a bark beetle outbreak has been successfully completed. The suppression treatments and fuel breaks described were conducted successfully. As a result, the Duck Creek Village Forest Stewardship Plan is in place to address long-term prevention measures that will reduce stand susceptibility to future mountain pine beetle attacks.

\section{The Upper South Platte Watershed Protection and Restoration Project, Pike-San Isabel National Forest and Mixed-Ownership Lands in Colorado}

The project objective was prevention and restoration of the Upper South Platte watershed for disturbances, including the mountain pine beetle and Douglas-fir beetle. The project area was approved in 1999, consists of 645,000 acres, and includes a critical Denver area watershed in need of restoration. Approximately 75 percent of the water supply for the areas 1.5 million inhabitants either originates or passes through the project boundaries. Major partners associated with this project include the USDA Forest Service, Denver Water Board, Colorado State Forest Service, USDA Environmental Protection Agency, and Colorado State University. Other participants also include: the U.S. Forest Service Rocky Mountain Research Station, local governments, and private landowners.

Over a 7-year period this watershed has experienced a number of large disturbances including:

- The 12,000 acre Buffalo Creek Fire in 1996.

- Severe erosion and siltation problems within existing impoundments and flowing waterways.

- Expanding noxious weed problems.

- A Douglas-fir tussock moth infestation.

- An increase in Douglas-fir beetle populations as a result of the previous insect defoliation and fire.

- Increasing populations of mountain pine beetle.

Project goals include:

- Reducing the risk of catastrophic wildfire.

- Preventing sediment and other water quality degradations within the watershed.

- Addressing resource and property-value losses associated with large-scale bark beetle infestations.

- Improving safety within the wildland/urban interface.

- Reducing noxious weed populations. 
Activities designed to meet the stated objectives include the use of prescribed fire, vegetative treatments (thinning and created openings), educational forums, and creating and maintaining snags and down logs. A Landscape Assessment Plan has been completed for the area, an oversight team has been identified, and fieldwork has begun. In the initial 5 year phase of the project, 8,000 acres have been identified to receive treatment.

\section{Restoration of Lodgepole Pine Stands on the Sawtooth National Recreation Area in Central Idaho}

Although not specifically designed as a bark beetle restoration project, a recent research project in the Sawtooth National Recreation Area (SNRA), central Idaho, embodies many principles of the restoration philosophy. Mountain pine beetles in the Sawtooth valley area operate much as they did in pre-Euro-American times. A sub-outbreak has been under way for the past 11 years. Due to climatic reasons, the population fails to reach full-blown outbreak proportions, but rather mortality is expressed in spatially distinct pockets. Management is primarily for recreation and scenic values; however, fuelwood harvest is an important commodity produced on the SNRA, with about 600 firewood harvest permits issued per year.

Managing this large number of individual permits has proven difficult. Permits are issued for standing-dead trees only, and mountain pine beetles are the main source of mortality. Since beetles pick trees independent of existing roads, firewood harvest was resulting in ad-hoc roads being created to reach beetle killed trees. These volunteer roads cause significant resource damage, including increased erosion in a critical salmon restoration watershed.

A research study was designed to use semiochemicals to focus bark beetle activity near existing roads. The killed trees could then be harvested without creating the ad-hoc roads. By targeting decadent stands for harvest, highly susceptible trees were removed from the ecosystem and a valuable product created by the beetles. Mortality is maintained within acceptable levels by the same climatic limitations that serve to keep the general beetle population at sub-outbreak levels. By targeting susceptible stands, the overall vigor and health of the forest is increased, biodiversity is enhanced, and a mosaic of age classes is created. Although this approach is not yet at the operational stage, it shows great promise for moving the landscape toward a sustainable configuration while at the same time solving a difficult forest management problem. These benefits were obtained through applying harvest and semiochemical treatments to manipulate bark beetle mortality to our advantage.

\section{A No-Action Strategy in Pinyon Pine on the Coconino National Forest in Arizona}

Severe drought in the Southwest during the winter of 1995 to 1996 resulted in several outbreaks of bark beetle, the pinyon Ips species, in northern Arizona. One of these outbreaks encompassed almost 13,000 acres of pinyon juniper woodland on the Coconino National Forest southeast of Flagstaff, Arizona.

Pinyon Ips is one of the most important tree mortality agents affecting pinyon species throughout the Intermountain region. As is typical for this insect, which undergoes several generations per year, the outbreak developed over a period of just a few months, and by the time it was reported, 
had already reached several thousand acres in size. While the mortality was spectacular, the outbreak was not suppressed for several reasons. First, outbreaks of this insect develop extremely rapidly and decline almost as rapidly, leaving little time for response with tools presently available. Second, the mortality was considered to be beneficial because recent expansion of pinyon/juniper woodlands, and associated increases in overstory density, have resulted in a corresponding decrease in valuable understory vegetation (grasses and forbs), which provide forage for cattle and wildlife species and protect soils from erosion. This understory vegetation is one of the most important resources within this ecosystem. Third, fire and fuels experts report that, under current conditions, it is very difficult to conduct burns within the pinyon/juniper woodlands due to the lack of fuels. Presence of some dead and down woody material on the ground in this instance could actually be beneficial, both to allow resource managers to conduct burns if desired and to provide badly needed organic material. Finally, this outbreak was located away from urban areas where tree mortality would be considered a threat. Pinyon mortality rates within the outbreak area were estimated to be over 70 percent, and trees as small as 2 inches in diameter were killed. Meanwhile, juniper trees in the area were unaffected, resulting in a shift in species composition.

On the one hand, this outbreak could be considered devastating if one only considers the fact that numerous trees were killed; however, looking at it from a broader perspective, the outbreak was actually beneficial in helping to move vegetative conditions in the area closer to desired conditions. This may not be the case in every pinyon Ips outbreak, but it does provide a case study of a situation where the no action alternative was appropriate.

\section{Mountain Pine Beetle Outbreak in the Vail Valley, Colorado}

The current mountain pine beetle outbreak in the Vail Valley of Colorado is not the first time that Summit and Eagle Counties have gone through a major bark beetle outbreak. An outbreak that occurred in Colorado from the mid-1970's to the early 1980's resulted in the "High Country Project." This project was a cooperative effort between local governments, the Colorado State Forest Service, and the USDA Forest Service to address extensive tree mortality. The attempt to directly reduce mortality had mixed results. But, in 1981, the "Summit/Upper Eagle Integrated Pest Management Environmental Assessment" was completed. This integrative document recognized that many of the lodgepole stands within the assessment area (including Vail) were in a state that was highly susceptible to bark beetle outbreaks. The analysis identified a great need for vegetation management throughout the area and recommended that a systematic series of cuttings be initiated to increase tree age and size class diversity.

A number of patchcuts and clearcuts were planned throughout the analysis area, and by the mid-1980's, these cuts were well under way. However, the rapid population increases in Colorado (particularly in Summit and Eagle Counties) resulted in a change in the local constituency. Residents who had witnessed the beetle outbreaks of the early 1980's were quickly outnumbered by new residents, who placed a great value on the "pristine" nature of the local forests. As time progressed, letters to the local Forest Service office and public comment on proposed actions grew increasingly negative. The adverse reaction to the preventive treatments reached such a crescendo that efforts to address existing stand conditions ended in 1991.

Within 5 years of ending the vegetation management program, mountain pine beetle populations began to increase in the Vail Valley in an outbreak that continues today. Needless to say, after experiencing several years of conspicuous and widespread bark beetle-caused tree mortality 
throughout the Vail Valley, most of the current calls to the local District office exhort the resource staff to "do something."

Because the situation in Vail is not unlike other beetle-impacted areas in the Rocky Mountains, public education opportunities abound for the Forest Service and its associates. 


\section{BARK BEETLE MANAGEMENT AND LAND-USE OPTIONS}

Forest conditions throughout the Rocky Mountain area have changed from their pre-EuroAmerican conditions. These changes are most obvious in those systems that are fire-maintained or fire-dependent, such as lodgepole or ponderosa pine. In other forest types, post-Euro-American management objectives or development have resulted in an intolerance of large-scale bark beetle outbreaks.

The question becomes, what can or should be done for management of bark beetles on these lands? The answer to this question is not simple, because the systems themselves are not simple. The current situation has resulted from over a century of fire prevention or other management activities that have inadvertently resulted in large landscapes vulnerable to bark beetle attack. The variety of interested publics, sometimes with conflicting views and opinions of appropriate management tactics, further complicate formulation of effective management strategies. The difficulty in formulating effective management response is highly dependent on specific land use objectives.

\section{Timber Production}

This objective equates the vigor and health of specific tree species with their commercial value. This management objective poses the least complexity in formulating bark beetle management strategies. The bark beetle management objectives for production forestry tend to be short term and operate at the stand level. Most past research has been focused on these temporal and spatial scales. The economic return from production forestry also justifies intensive management. The case history documentation of the State lands in the Idaho Panhandle illustrate the aggressive management response that that can be effectively formulated for bark beetle control to meet this objective.

\section{URBAN/WILDLAND INTERFACE}

Where residential development abuts or includes forested lands, the presence of mature trees is seen as an enhancement to land values. The high value of individual trees in this setting allows use of tactics that are prohibitively expensive in most other situations. The effective use of pesticides, for example, was illustrated in southern Utah case history (see page 28). However, conflicting human expectations complicate bark beetle management in the urban/wildland interface, as illustrated by Vail, Colorado, case history (see page 31 ).

\section{Wilderness and Roadless Areas}

The land-use objectives for designated wilderness and roadless areas are to provide landscapes where natural processes are promoted with varying restrictions on human influence. Effective bark beetle management becomes less clear for these objectives. The no action option in Wilderness settings that are far removed from developed lands may be preferred. In these settings, outbreaks may be viewed as a normal part of forest succession. Some landscapes, however, may have become so altered by previous management practices that long timeframes may be necessary to achieve 
ecological sustainability. Management practices may need to be implemented during this timeframe. Additional research is needed to more clearly elucidate the ecological role of bark beetles, and the interaction between disturbances, in order to determine characteristics of landscapes that could benefit from management intervention.

Wilderness or roadless areas near developed or commercial lands pose special problems. In these situations, research is needed to determine the characteristics of effective buffers between landscapes where outbreaks operating in an ecological context are accepted compared to those where high mortality is not acceptable. Effective plans will require various ownerships in and near wilderness and roadless areas to develop complimentary long-term prevention strategies to reduce susceptibility on these adjoining lands.

\section{Wildlife Management}

This objective centers around providing forest habitat for wildlife species. As previously mentioned, habitat requirements of some threatened and endangered species coincide with those that increase risk of bark beetle outbreaks. In these situations, management strategies need to be developed that result in a mosaic of susceptibility classes. The objective is to develop a succesional patchwork that provides a critical level of habitat at all times, even though the landscape pattern itself is dynamic. Such strategies require additional research into the response of wildlife species to varying levels of management and beetle population impact. Models capable of predicting the spatial dynamics of bark beetle outbreaks, forest succession, and the interaction between them are also needed.

\section{Multiple OWNerships ANd Use}

This objective attempts to balance the demands of multiple users of forest lands. For purposes of bark beetle population mangement, this many-sided objective is further complicated in areas where multiple land ownerships exist.

The Rocky Mountain area consists of a patchwork of Federal, State, and privately owned and managed lands. Forest health managers need to develop maximum flexibility regarding policy in order to identify the best and most efficient ways to address forest condition and bark beetle concerns. Partnerships between the various interested parties need to be developed prior to bark beetle outbreaks so that pro-active projects can be initiated and contingency plans developed. A number of pilot projects, such as Upper Platte Watershed Project in Colorado, have begun, which address these needs. This process needs support from governmental agencies in order to become standard procedure. Additional research is needed to determine the long-term effects of thinning tactics that have proven effective for mountain pine beetle in short-term rotations. These silvicultural treatments need to be evaluated for a wider range of bark beetle species and host types. 


\section{ISSUES NEEDS AND RECOMMENDATIONS}

\section{Public Involvement}

There is a need for improved and expanded education on the part of the general public to come to an understanding of general forest ecology, composition, and succession. This includes an understanding of the interactions of all aspects of the forest, both abiotic and biotic components, including that of bark beetles. Too often, the perception is that the forest will never change, that the conditions seen at the moment will always be present. In reality, change is constantly taking place in the forests. This is due to many factors, including but not limited to fire, insects, diseases, weather events, aging, and succession. Thus, the forests of today will not be the forests of tomorrow. Too often, people do not understand that the above-mentioned disturbance factors are primary agents of change when viewed on an ecological perspective. The insects and diseases are classified as "pests" only when they create conflict with our objectives. It is when this happens that management solutions need to be implemented.

A case in point is the current mountain pine beetle outbreak near Vail, Colorado (see the description on page 31). The wildland/urban interface in Vail is an area where bark beetles may be classified as a pest and as such should be managed. Education is needed to help the public differentiate between bark beetle outbreaks in areas where their ecological role is an important component that should be maintained and those areas where beetle killed-mortality is in conflict with resource objectives.

Need: Public education.

Recommendation: Coordinate with interested natural resource agencies and others to initiate or improve educational programs on three levels — national, regional, and local — to highlight the dynamic nature of forests, including the roles of disturbance agents (e.g., bark beetles, fire, and diseases) and management options (prevention, suppression, restoration, and no action) for various forest settings. Use television, radio, websites, news/public information releases in newspapers, speaking engagements, public meetings, and field days to provide multiple opportunities and media for information distribution.

\section{RESEARCH}

Bark beetle species have been the subject of extensive research due to the economic impact of outbreaks. Because a large proportion of the information was focused on the pest status of bark beetles, important knowledge gaps exist regarding basic ecological processes for even the most important species. Additionally, information on silvicultural strategies for management of the major species is still lacking. Key areas where research is needed include:

- Effective management tools that can be used in the urban/wildland interface.

- The role of specific semiochemicals, especially antiaggregants, in bark beetle population ecology.

- Basic ecological information regarding the interaction between disturbance agents, such as bark beetles and fire. 
- Population response of the major bark beetle species to thinning at all scales.

- Long-term ecological impacts of both bark beetle outbreaks and the management responses to outbreaks.

- Statistical analysis and spatial modeling of bark beetle populations for implementation in risk-rating systems.

- Restoration techniques, including prescribed fire, and how they can be used to enable forest ecosystems to be more resilient to bark beetle populations.

- The role of ownership pattern mosaics in bark beetle outbreak evolution, and complementary strategies that can be used by diverse land managers for reducing susceptibility on adjacent landscapes.

- Understanding the effect of climate change on the outbreak potential of important bark beetle species.

Need: Continued support for bark beetle basic and applied research.

Recommendation: Implement research projects to address the identified knowledge gaps in order to meet short- and long-term needs of forest managers.

\section{Technology DeVelopment}

In the past, technology development has focused on visual assessment and direct intervention techniques for control of bark beetle outbreaks. Newer methods of assessment and response are now being developed but must be tested and distributed to verify their applicability. A concerted effort needs to be made to identify all available methodologies, document them, and prepare technology transfer tools.

Advancements in remote sensing technology, for example, have recently been made. These advancements include electronic sketch mapping, satellites with higher spatial resolution, airborne detection sensors, and new analysis tools for detecting previsual stress indicators. This combination of tools needs to be evaluated and integrated into the annual forest insect monitoring program to allow for more accurate information on bark beetle population status in each region and, ultimately, improved risk-mapping.

Need: Improved remote sensing applications and other technologies.

Recommendation: Support projects to transfer existing remote sensing tools to bark beetle management, and evaluate other emerging technologies.

\section{Resource Management}

Existing forest conditions reflect the management or lack of management of the past 50 years. As basic understanding of bark beetle biology has increased, so has the potential for utilizing this knowledge to better manage bark beetle activity. Direct controls of bark beetles include the use of pesticides, semiochemicals, and harvesting. Preventive tools, including silvicultural manipulation and fire, can reduce the occurrence of forest pest problems. 
Resource managers are confronted with a variety of resource values, some of which are not compatible. The rapid growth of the human population in the Rocky Mountain region will impact future management options. Effective tools for management in the wildland/urban interface are a high priority.

Need: Management strategies.

Recommendation: Research and develop strategies and techniques to meet the goals of sustainable resource values (wildlife, recreation, sensitive species, etc.) in all forest lands.

Need: Ability to implement proven bark beetle management strategies when these approaches are warranted.

Recommendation: Secure public support for management strategies and techniques through more effective education, dialogue, and representation in the decisionmaking process. Too often we have management techniques that would be effective but are limited in our ability to implement them (see the Vail Valley case history, page 31). 


\section{REFERENCES}

\section{Social ANd Ecological Influences on Forest Ecology}

Barrett, S.W. and S.F. Arno. 1982. Indian fires as an ecological influence in the northern Rockies. J. Forestry 80: 647-651.

Covington, W.W. and M.M. Moore. 1994. Southwestern ponderosa pine forest structure: changes since Euro-America settlement. J. Forestry. 92: 39-47.

Gara, R.I., W.R. Littke, J.K. Agee, D.R. Geiszler, J.D. Stuart, and C.H. Driver. 1985. Influence of fires, fungi, and mountain pine beetles on development of a lodgepole pine forest in southcentral Oregon. pp. 153-162 in Baumgartner, D.M., D.M. Krebill, R.G. Arnott, J.T. Weetman and F. Gordon, eds. Lodgepole pine: the species and its management: symposium proceedings; 1984 May 8-10; Spokane, Wash.; 1984 May 14-16: Vancouver, BC. Pullman, Wash.: Office of Conferences and Institutes, Cooperative Extension.

Gruell, G.E. 1983. Fire and vegetative trends in the northern Rockies: Interpretation from 18711981. USDA Forest Service. Gen. Tech. Rep. INT-158, Ogden, Utah.

MacCleery, D.W. 1992. A history of resiliency and recovery. USDA Forest Service. Publication 540. Washington D.C. $59 \mathrm{pp}$.

Progulske, D.R. 1974. Yellow ore, yellow hair, yellow pine: a photographic study of a century of forest ecology. Bull. No. 616. Agricultural Experiment Station, South Dakota State University, Brookings, S.D. 171 pp.

Riebsame, W.E., ed. 1997. Atlas of the new west: portrait of a changing region. W. W. Norton, New York.

Romme, W.H., D.H. Knight and J.B. Yavitt. 1986. Mountain pine beetle outbreaks in the Rocky Mountains: regulators of primary production? Am. Nat. 127(4): 484-494.

Veblen, T.T. and D.C. Lorenz. 1991. The Colorado Front Range: a century of ecological change. University of Utah Press. Salt Lake City, Utah. 188 pp.

\section{EcologicAl EFFects}

Amman, G.D. 1978. The role of the mountain pine beetle in lodgepole pine ecosystems: Impact of succession, pp. 3-18 in W.J. Mattson, ed. The Role of Arthropods in Forest Ecosystems. Springer-Verlag, New York.

Baker, W.L. and T.T. Veblen. 1980. Spruce beetles and fires in the nineteenth-century subalpine forests of western Colorado, U.S.A. Arctic and Alpine Research 22(1):65-80.

Cole, W.E. and G.D. Amman. 1980. Mountain pine beetle dynamics in lodgepole pine forests part 1: Course of an infestation. USDA Forest Service. Gen. Tech. Rep. INT-89. 
Long, J.N. 1994. The middle and southern Rocky Mountain Region. pp 335-386 in J.W. Barrett, ed. Regional Silviculture of the United States, John Wiley \& Sons, Inc.

Perry, D.A. and M.P. Amaranthus. 1997. Disturbance, recovery, and stability. pp. 31-56 in K.A. Kohm and J.F. Franklin, eds. Creating a Forestry for the $21^{\text {st }}$ Century. Island Press, Washington, D.C.

Peterman, R.M. 1978. The ecological role of mountain pine beetle in lodgepole pine forests. pp. 16-26 in A.A. Berryman, G.D. Amman and R.W. Stark, eds. Theory and Practice of Mountain Pine Beetle Management in Lodgepole Pine Forests. Forest, Wildlife and Range Experiment Station, University of Idaho, Moscow, ID.

Schmid, J.M. and T.E. Hinds. 1974. Development of spruce-fir stands following spruce beetle outbreaks. USDA Forest Service. Res. Pap. RM-131.

Schmid, J.M. and S.A. Mata. 1996. Natural variability of specific forest insect populations and their associated effects in Colorado. USDA Forest Service. Gen. Tech. Rep. RM-275.

Schowalter, T., E. Hansen, R. Molina and Y. Zhang. 1997. Integrating the ecological roles of phytophagous insects, plant pathogens, and mycorrhizae in managed forests. pp. 171-190 in K.A. Kohm and J.F. Franklin, eds. Creating a Forestry for the $21^{\text {st }}$ Century. Island Press, Washington, D.C.

Spies, T. 1997. Forest stand structure, composition, and function. pp. 11-30 in K.A. Kohm and J.F. Franklin, eds. Creating a Forestry for the $21^{\text {st }}$ Century. Island Press, Washington, D.C.

Stone, W.E. and M.L. Wolfe. 1996. Response of understory vegetation to variable tree mortality following a mountain pine beetle epidemic in lodgepole pine stands in northern Utah. Vegetatio 122:1-12.

Veblen, T.T., K.S. Hadley, E.M. Nel, T. Kitzberger, M. Reid and R. Villalba. 1994. Disturbance regime and disturbance interactions in a Rocky Mountain subalpine forest. J. Ecology $82: 125-135$.

\section{Modeling}

Logan, J.A. and B.J. Bentz. 1999. Model analysis of mountain pine beetle seasonality. Environ. Entomol. (Forum article) 28: 924-934.

Logan, J.A., P. White, B.J. Bentz and J.A. Powell. 1998. Model analysis of the temporal evolution of spatial patterns in mountain pine beetle outbreaks. Theor. Popul. Biol. 53: 236-255.

Safranyik, L., H. Barclay, A. Thomson and W. G. Riel. 1999. A population dynamics model for the mountain pine beetle, Dendroctonus ponderosae Hopk. (Coleoptrea: Scolytidae). Information Repotr BC-X-386, Pacific Forestry Centre, Victoria, BC.

Powell, J.A., J.A. Logan and B.J. Bentz. 1996. Local projections for a global model of mountain pine beetle attacks. J. Theor. Biol. 179: 243-260. 
Powell, J. A., J. Tams, B. J. Bentz and J. A. Logan. 1998. Theoretical analysis of "switching" in a localized model for mountain pine beetle mass attack. J. Theor. Biol. 194: 49-63.

\section{Vegetation Management/Suppression/Prevention}

Alexander, R.R. 1987. Silvicultural systems, cutting methods, and cultural practices for Black Hills ponderosa pine. USDA Forest Service. Gen. Tech. Rep. RM-139. Rocky Mountain Forest and Range Exp. Station, Ft. Collins, Colo. 32 pp.

Amman, G.D. 1983. Strategy for reducing mountain pine beetle infestations with ponderosa pine trap logs. USDA Forest Service. RN INT-338. Intermountain Forest and Range Exp. Station, Ogden, Utah. 3 pp.

Amman, G.D., G.D. Lessard, L.A. Rasmussen and C.G. O’Neil. 1988. Lodgepole pine vigor, regeneration, and infestation following partial cutting on the Shoshone National Forest, Wyoming. USDA Forest Service, Res. Pap. INT-396. Intermountain Forest and Range Exp. Station, Ogden, Utah.

Amman, G. D. and J. A. Logan. 1998. Silvicultural control of the mountain pine beetle: prescriptions and the influence of microclimate. Am. Entomol. 44: 166-177.

Amman, G.D., M.D. McGregor, D.B. Cahill and W.H. Klein. 1977. Guidelines for reducing losses of lodgepole pine to the mountain pine beetle in unmanaged stands in the Rocky Mountains. USDA Forest Service. Gen. Tech. Rep. INT-36, Intermountain Forest and Range Exp. Station, Ogden, Utah. 19 pp.

Amman, G.D., M.D. McGregor and R.E. Dolph Jr. 1989. Mountain pine beetle. USDA Forest Service, Forest Insect \& Disease Leaflet \#2, Washington, D.C., 11 pp.

Amman, G.D., M.D. McGregor, R.F. Schmitz and R.D. Oakes. 1988. Susceptibility of lodgepole pine to infestation by mountain pine beetles following partial cutting of stands. Can. J. For. Res. 18: 688-695.

Anhold, J.A. and M.J. Jenkins. 1987. Potential mountain pine beetle (Coleoptera: Scolytidae) attack of lodgepole pine as described by stand density index. J. Env. Ent. 16(3): 738-742.

Anhold, J.A., M.J. Jenkins and J.N. Long. 1996. Management of lodgepole pine stand density to reduce susceptibility to mountain pine beetle attack. West. J. Appl. For. 11(2): 50-53.

Bartos, D.L. and G.D. Amman. 1989. Microclimate: An alternative to tree vigor as a basis for mountain pine beetle infestations. USDA Forest Service. Res. Pap. INT-400. Intermountain Forest and Range Exp. Station, Ogden, Utah. 10 pp.

Bartos, D.L. and G.D. Booth. 1994. Effects of thinning on temperature dynamics and mountain pine beetle activity in a lodgepole pine stand. USDA Forest Service. Res. Pap. INT-RP479. Intermountain Res. Station, Ogden, Utah. 9 pp. 
Borden, J.H. 1989. Semiochemicals and bark beetle populations: Exploitation of natural phenomena by pest management strategists. Holarct. Ecol. 12: 501-510.

Borden, J.H., L.J. Chong, K.E.G. Pratt and D.R. Gray. 1983. The application of behavior-modifying chemicals to contain infestations of the mountain pine beetle, Dendroctonus ponderosae. Forestry Chronicle 235-239.

Cahill, D.B. 1978. Cutting strategies as control measure of the mountain pine beetle in lodgepole pine in Colorado. pp. 188-191 in A.A. Berryman, G.D. Amman, R.W. Stark, eds. Proceedings, Symposium: Theory and practice of mountain pine beetle management in lodgepole pine forests. Moscow, Idaho: University of Idaho, Forest, Wildlife and Range Exp. Station, April 25-27, 1978, Pullman, Wash.

Cole, D.M. 1978. Feasibility of silvicultural practices for reducing losses to the mountain pine beetle in lodgepole pine forests. pp. 140-147 in A.A. Berryman, G.D. Amman and R.W. Stark, eds. Proceedings, Symposium: Theory and Practice of Mountain Pine Beetle Management in Lodgepole Pine Forests. Moscow, Idaho: University of Idaho, Forest, Wildlife and Range Exp. Station, April 25-27, 1978, Pullman, Wash..

Cole, D.M. 1985. Acceptable silvicultural systems in relation to desired stand character and successional roles of lodgepole pine. pp. 45-46 in M.D. McGregor and D.M. Cole, eds. Proceedings, Integrating management strategies for the mountain pine beetle with multipleresource management of lodgepole pine forests. Gen. Tech. Rep. INT-174. Intermountain Forest and Range Experiment Station, Ogden, Utah.

Cole, W.E., D.B. Cahill and G.D. Lessard. 1983. Harvesting strategies for management of mountain pine beetle infestations in lodgepole pine: preliminary evaluation, East Long Creek demonstration area, Shoshone National Forest, Wyoming. USDA Forest Service, Res. Note INT-333, Intermountain Res. Station. 11 pp.

Covington, W.W., P.Z. Fule, M.M. Moore, S.C. Hart, T.W. Kolb, J.N. Mast, S.S. Sackett and M.R.Wagner. 1997. Restoring ecosystem health in ponderosa pine forests of the Southwest. J. Forestry 94(3): 23-29.

Eaton, C.B. 1959. Insect-caused mortality in relation to methods of cutting in ponderosa pine on the Blacks Mountain Experimental Forest. USDA Forest Service. Tech. Pap. 43. Pacific Southwest Forest and Range Exp. Station, Berkeley, Calif. 33 pp.

Gibson, K.E. 1994. Bark beetle pheromone use in the USDA Forest Service's Northern Region. pp. 28-32 in Proceedings, Symposium: Management of Bark Beetles with Pheromones: Research and development, June 22-25, 1992, Kailua-Kona, Hawaii, Gen. Tech. Rep. PSW-GTR150, USDA Forest Service, Berkeley, Calif.

Gibson, K.E. and D.D. Bennett. 1985. Effectiveness of carbaryl in preventing attacks on lodgepole pine by the mountain pine beetle. J. Forestry 83: 109-112.

Goyer, R.A., M.R. Wagner, and T.D. Schowalter. 1998. Current and proposed technologies for bark beetle management. J. Forestry 96(12): 29-33. 
Gray, D.R., E. Holsten and M. Pascuzzo. 1990. Effects of semiochemical baiting on the attractiveness of felled and unfelled lethal trap trees for spruce beetle, Dendroctonus rufipennis (Kirby) (Coleoptera: Scolytidae), management in areas of high and low beetle populations. Can. Ent. 122: 373-379.

Hall, R.W., P.J. Shea and M.I. Haverty. 1981. Effectiveness of carbaryl and chlorpyriphos for protecting ponderosa pine trees from attack by the western pine beetle (Coleoptera: Scolytidae). J. Econ. Ent. 75: 504-508.

Hamel, D.R. 1978. Results of harvesting strategies for management of mountain pine beetle infestations in lodgepole pine on the Gallatin National Forest, Montana. pp. 192-196 in A.A. Berryman, G.D. Amman, R.W. Stark, (eds.), Proceedings, Symposium: Theory and practice of mountain pine beetle management in lodgepole pine forests. Moscow, Idaho: University of Idaho, Forest, Wildlife and Range Exp. Station, April 25-27, 1978, Pullman, Wash.

Haverty, M.I., P.J. Shea and R.W. Hall. 1985. Effective residual life of carbaryl for protecting ponderosa pine from attack by the western pine beetle (Coleoptera: Scolytidae). J. Econ. Ent. 78: 197-199.

Haverty, M.I., P.J. Shea, J.T. Hoffman, J.M. Wenz and K.E. Gibson. 1998. Effectiveness of esfenvalerate, cyfluthrin, and carbaryl in protecting individual lodgepole and ponderosa pines from attack by Dendroctonus spp. USDA Forest Service. Res. Pap. PSW-RP-237. Pacific Southwest Research Station, Berkeley, Calif. 17 pp.

Holsten, E.H., R.W. Thier, A.S. Munson and K.E. Gibson. 1999. The spruce beetle. USDA Forest Service, Forest Insect \& Disease Leaflet \#127, Washington, D.C., 12 pp.

Jenkins, M.J., C.A. Dicus and E.G. Hebertson. 1998. Postfire succession and disturbance interactions on an intermountain subalpine spruce-fir forest. pp. 219-229 in Pruden, T.L. and L.A. Brennan, eds. Proceedings, Symposium: Fire in Ecosystem Management: Shifting the paradigm from suppression to prescription. Tall Timbers Fire Ecology Conference Proceedings, No. 20. Tall Timbers Research Station, Tallahassee, FL.

Keen, F.P. 1958. Progress in bark beetle control through silviculture in the United States. In: Proceedings, Tenth International Congress of Entomology. 4(1956): 171-180.

Klein, W.H. 1978. Strategies and tactics for reducing losses in lodgepole pine to the mountain pine beetle by chemical and mechanical means. pp. 54-63 in A.A. Berryman, G.D. Amman and R.W. Stark, eds. Proceedings, Symposium: Theory and Practice of Mountain Pine Beetle Management in Lodgepole Pine Forests. Moscow, Idaho: University of Idaho, Forest, Wildlife and Range Exp. Station, April 25-27, 1978, Pullman, Wash.

McCambridge, W.F. and R.E. Stevens. 1982. Effectiveness of thinning ponderosa pine stands in reducing mountain pine beetle mortality-preliminary observations. USDA Forest Service, Res. Note RM-414, Rocky Mtn. Forest and Range Exp. Station, Ft. Collins, Colo. 3 pp. 
McGregor, M.D. 1985. Practices and considerations for noncommercial forests. pp. 56-58 in McGregor, M.D. and D.M. Cole eds. Proceedings, Integrating management strategies for the mountain pine beetle with multiple-resource management of lodgepole pine forests, Gen. Tech. Rep. INT-174. Intermountain Forest and Range Experiment Station, Ogden, Utah.

McGregor, M.D. 1985. Silvicultural practices for lodgepole pine stands in commercial forests. pp. 47-55 in McGregor, M.D. and D.M. Cole, ed. Proceedings, Integrating management strategies for the mountain pine beetle with multiple

$n$ McGregor, M.D. and D.M. Cole, eds. Proceedings, Integrating management strategies for the mountain pine beetle with multiple-resource management of lodgepole pine forests, Gen. Tech. Rep. INT-174. Intermountain Forest and Range Experiment Station, Ogden, Utah.

McGregor, M.D. and W.E. Cole. 1985. Integrating management strategies for the mountain pine beetle with multiple resource management of lodgepole pine Forests. USDA Forest Service. Gen. Tech. Rep. INT-174. Intermountain Forest and Range Exp. Station, Ogden, Utah. $68 \mathrm{pp}$.

McGregor, M.D., M.M. Furniss, R.D. Oakes, K.E. Gibson and H.E. Meyer. 1984. MCH pheromone for preventing Douglas-fir beetle infestation in windthrown trees. J. Forestry. 83: 613-616.

Mitchell, R.G. 1989. Mixed host strategies for mountain pine beetle control in Oregon. pp. 60-63 in G.D. Amman, ed. Proceedings, Symposium: On the management of lodgepole pine to minimize losses to the mountain pine beetle. Gen. Tech. Rep. INT-262. 119 pp.

Mitchell, R.G., R.H. Waring and G.B. Pitman. 1983. Thinning lodgepole pine increases tree vigor and resistance to mountain pine beetle. For. Sci. 29:204-211.

Nagel, R.H., D. McComb and F.B. Knight. 1957. Trap tree method for controlling the Engelmann spruce beetle in Colorado. J. Forestry. 55(12): 894-898.

Nebecker, T.E. and J.D. Hodges. 1983. Influence of forestry practices on host-susceptibility to bark beetles. Zeitschrift fur Angewandte Entomologie. 96:194-208.

Olsen, W.K., J.M. Schmid and S.A. Mata. 1996. Stand characteristics associated with mountain pine beetle infestations. For. Sci. 42(3): 310-327.

Page, M., M.I. Haverty and C.E. Richmond. 1985. Residual activity of carbaryl protected lodgepole pine against mountain pine beetle, Dillon, Colorado, 1982 and 1983. USDA Forest Service, Res. Note. PSW-375. Pacific Southwest Forest and Range Exp. Station, Berkeley, Calif. $4 \mathrm{pp}$.

Patterson, J.E. 1930. Control of the mountain pine beetle in lodgepole pine by the use of solar heat. USDA Forest Service, Tech. Bull. 195, Washington, D.C. 20 pp.

Pitman, G.B., D.A. Perry and W.H. Emmingham. 1982. Thinning to prevent lodgepole pine beetles in lodgepole pine and ponderosa pine. Oregon State University Ext. Service, The Woodland Workbook, Ext. Cir. 1106. 4 pp. 
Ross, D.W., K.E. Gibson, R.W. Their and A.S. Munson. 1996. Optimal dose of an antiaggregation pheromone (3-methylcyclohex-2-en-1-one) for protecting live Douglas-fir from attack by Dendroctonus pseudotsugae (Coleoptera: Scolytidae). J. Econ. Ent. 89: 1,204-1,207.

Ross, D.W. and C.G. Niwa. 1997. Using aggregation and antiaggregation pheromones of the Douglasfir beetle to produce snags for wildlife habitat. Western J. Appl. Forestry. 12: 52-54.

Safranyik, L. 1982. Alternative solutions-Preventive management and direct control. pp. 29-32 in Shrimpton, D.M., ed. Proceedings, Joint Canada-United States Workshop on Mountain Pine Beetle Related Problems in Western North America, BC-X-230. Pacific Forest Research Centre, Victoria, BC.

Safranyik, L., D.M. Shrimpton and H.S. Whitney. 1974. Management of lodgepole pine to reduce losses from the mountain pine beetle. Canadian Forest Service, Tech. Rep. 1. Pacific Forest Research Centre, Department of the Environment, Victoria, B.C. 24 pp.

Sartwell, C. 1971. Thinning ponderosa pine to prevent outbreaks of mountain pine beetle. pp. 4152 in D.M. Baumgartner, ed. Proceedings, Precommercial thinning of Coastal and Intermountain Forests in the Pacific Northwest. Washington State Univ. Coop. Ext. Ser., Feb. 3-4, 1971, Pullman, Wash.

Sartwell, C. and R.E. Stevens. 1975. Mountain pine beetle in ponderosa pine: Prospects for silvicultural control in second-growth stands. J. Forestry. 73: 136-140.

Schmid, J.M. 1987. Partial cutting in MPB-susceptible stands: Will it work and for how long? pp. 243-245 in Proceedings, Management of subalpine forests: Building on 50 years of forest research. USDA Forest Service, July 6-9, 1987, Silver Creek, Colo. Gen. Tech. Rep. RM149. Ft. Collins, Colo.

Schmid, J.M. and R.H. Frye. 1977. Spruce beetle in the Rockies. USDA Forest Service, Gen. Tech. Rep. RM-49. Rocky Mountain Forest and Range Exp. Station, Ft. Collins, Colo. 38 pp.

Schmid, J.M. and S.A. Mata. 1992. Stand density and mountain pine beetle-caused tree mortality in ponderosa pine stands. USDA Forest Service, Res. Note RM-515. Rocky Mountain Forest and Range Exp. Station, Ft. Collins, Colo. 4 pp.

Schmidt, W.C. 1982. Alternative solutions to the mountain pine beetle-The silviculture perspective. pp. 33-40 in Shrimpton, D.M., ed. Proceedings, Joint Canada-United States Workshop on Mountain Pine Beetle Related Problems in Western North America, BC-X-230. Pacific Forest Research Centre, Victoria, BC.

Schmitz, R.F. and K.E. Gibson. 1996. Douglas-fir beetle. USDA Forest Service, Forest Insect \& Disease Leaflet \#5, Washington, D.C. 8 pp.

Setter, R.R. and J.H. Borden. 1999. Bioactivity and efficacy of MCOL and seudenol as potential attractive bait components for Dendroctonus rufipennis (Coleoptera: Scolytidae). Can. Ent. 131: 251-257. 
Shea, P.J., M.I. Haverty and R.W. Hall. 1984. Effectiveness of fenitrothion and permethrin for protecting ponderosa pine from attack by western pine beetle. J. Georgia Ent. Society 19: 427-433.

Shea, P.J. and M.D. McGregor. 1987. A new formulation and reduced rates of carbaryl for protecting lodgepole pine from mountain pine beetle attack. Western J. Applied Forestry 2: 114-116.

Shea, P.J. and M. Neustein. 1995. Protection of a rare stand of Torrey pine from Ips paraconfusus. Application of semiochemicals for management of bark beetle infestations. pp. 39-43 in S.M. Salom and K.R. Hobson, eds. Proceedings, An informal conference. Gen. Tech. Rep. INT-GTR-318. USDA Forest Service, Intermountain Research Station, Ogden, Utah.

Smith, R.H., G.C. Trostle and W.F. McCambridge. 1977. Protective sprays on three species of bark beetles in the western United States. J. Econ. Ent. 70:119-125.

Society of American Foresters. 1998. The Dictionay of Forestry, ed. John Helms.

Stevens, R.E., C.A. Meyers, W.F. McCambridge, G.L. Downing and J.G. Laut. 1974. Mountain pine beetle in front range ponderosa pine: What it's doing and how to control it. USDA Forest Service. Tech. Rep. RM-7. Rocky Mountain Forest and Range Exp. Station, Ft. Collins, Colo.

Thier, R.W. 1994. Chronology of the current spruce beetle infestation on the Payette National Forest, Idaho. USDA Forest Service. FHP Rep. R4-94-02. Boise, Idaho. 23 pp.

Waring, R.H. and G.B. Pitman. 1985. Modifying lodgepole pine stands to change susceptibility to mountain pine beetle. Ecology 66:889-897.

\section{Decision Support Systems}

Furniss, R.L. and V.M. Carolin. 1977. Western forest insects. USDA Forest Service. Misc. Pub. $\# 1339$.

Reynolds, K.M. and E.H. Holsten. 1997. SBexpert User Guide (Version 2.0): A Knowledge- Based Decision- Support System for Spruce Beetle Management. USDA Forest Service. Pacific Northwest Research Station, Gen. Tech. Rep. PNW-GTR-401. 62 pp.

Schmid, J.M. and R.H. Frye. 1976. Stand ratings for spruce beetles. USDA Forest Service. Res. Note RM-309.

Shore, T.L. and L. Safranyik. 1992. Susceptibility and risk rating systems for the mountain pine beetle in lodgepole pine stands. For. Canada, BC-X-336.

Steele, R., R.E. Williams, J.C. Weatherby, E.D. Reinhardt, J.T. Hoffman and R.W. Thier. 1996. Stand hazard rating for central Idaho forests. USDA Forest Service. Gen. Tech. Rep. INTGTR-332. Intermountain Res. Station. 29 pp. 
Stevens, R.E., W.F. McCambridge and C.B. Edminster. 1980. Risk rating guide for mountain pine beetle in Black Hills ponderosa pine. USDA Forest Service. Res. Note RM-385.

Weatherby, J.C. and R.W. Their. 1993. A preliminary validation of a Douglas-fir beetle Hazard rating system, Mountain Home Ranger District, Boise National Forest. USDA Forest Service. FPM Rep., R4-93-05.

\section{Assessments}

Carter, C.A., W.G. Cibula and R.L. Miller. 1996. Narrow-band reflectance imagery compared with thermal imagery for early detection of plant stress. J. Plant Physiol. 148: 515 - 522.

Dillman, R.D., S.S. Chu, B.B. Eav and J.C. Prill. 1980. A pilot test of high altitude optical bar camera photography to estimate annual mortatity of ponderosa pine caused by the mountain pine beetle in Colorado. Aerial Photography Technology, Development and Application Support Project: Stage III, Final Rep., USDA Forest Service Contract: 53-3187-8-25. Lockheed Eng. and Mgt. Ser. Co.-14308. 56 pp.

Johnson, J., P. Greenfield and A.S. Munson. 1998. An evaluation of the utility of sub-pixel analysis of thematic mapper imagery for the spruce beetle outbreak on the Manti-LaSal National Forest. pp. 276-287 in J.D. Greer, ed. Proceedings, Seventh Forest Service Remote Sensing Applications Conference. Salt Lake City, Utah: USDA Forest Service, Remote Sensing Application Center, Nacogdoches, Texas: Stephen F. Austin State University. April 6-10, 1998, Nassau Bay, Texas.

Schrader-Patten, C. 2000. Digital aerial sketch-mapping. (Interim Project Report), Remote Sensing Application Center, Salt Lake City, Utah. 15 pp.

Weber, F.P. 1972. Remote sensing to detect stress in forests. Photogrammetric Engineering, Feb. 1972: 163-175. 
The U.S. Department of Agriculture (USDA) prohibits discrimination in all its programs and activities on the basis of race, color, national origin, sex, religion, age, disability, political beliefs, sexual orientation, or marital or family status. (Not all prohibited bases apply to all programs.) Persons with disabilities who require alternative means for communication of program information (Braille, large print, audiotape, etc.) should contact USDA's TARGET Center at (202) 720-2600 (voice and TDD).

To file a complaint of discrimination, write USDA, Director, Office of Civil Rights, Room 326-W, Whitten Building, 1400 Independence Avenue, SW, Washington, DC 20250-9410 or call (202) 720-5964 (voice or TDD). USDA is an equal opportunity provider and employer. 